\title{
Hydrogen Production from Formic Acid Attained by Bimetallic Heterogeneous PdAg Catalytic Systems
}

\author{
Miriam Navlani-García ${ }^{1, * \mathbb{C}}$, David Salinas-Torres ${ }^{2}$ and Diego Cazorla-Amorós ${ }^{1}$ \\ 1 Department of Inorganic Chemistry and Materials Institute, University of Alicante, 03080 Alicante, Spain; \\ cazorla@ua.es \\ 2 Department of Physical Chemistry and Materials Institute, University of Alicante, 03080 Alicante, Spain; \\ david.salinas@ua.es \\ * Correspondence: miriam.navlani@ua.es; Tel.: +34-965-903-400 (ext. 9150)
}

Received: 26 September 2019; Accepted: 21 October 2019; Published: 23 October 2019

\begin{abstract}
The production of $\mathrm{H}_{2}$ from the so-called Liquid Organic Hydrogen Carriers (LOHC) has recently received great focus as an auspicious option to conventional hydrogen storage technologies. Among them, formic acid, the simplest carboxylic acid, has recently emerged as one of the most promising candidates. Catalysts based on Pd nanoparticles are the most fruitfully investigated, and, more specifically, excellent results have been achieved with bimetallic PdAg-based catalytic systems. The enhancement displayed by PdAg catalysts as compared to the monometallic counterpart is ascribed to several effects, such as the formation of electron-rich Pd species or the increased resistance against CO-poisoning. Aside from the features of the metal active phases, the properties of the selected support also play an important role in determining the final catalytic performance. Among them, the use of carbon materials has resulted in great interest by virtue of their outstanding properties and versatility. In the present review, some of the most representative investigations dealing with the design of high-performance PdAg bimetallic heterogeneous catalysts are summarised, paying attention to the impact of the features of the support in the final ability of the catalysts towards the production of $\mathrm{H}_{2}$ from formic acid.
\end{abstract}

Keywords: hydrogen production; formic acid; heterogeneous catalysts; bimetallic nanoparticles; PdAg; AgPd; alloy

\section{Introduction}

If we think about the major problems faced by mankind, many socio-political matters, such as the economy, wars, terrorism, etc., would come to our minds. However, people are much less aware of environmental issues, which, for some people, are still a remote concept far from being within their concerns. Even if we do not "perceive" the global warming in our day-to-day existence, catastrophic consequences, such as the ozone depletion, or the extinction of species and destruction of marine habitat and deforestation, are a fact that jeopardises the continuity of our life as we know it nowadays. Never before our planet and existence have depended to such an extent on how we cope with climate change. Creating a sustainable world society is mandatory to reduce the human impact on nature, and using scientific knowledge as a guide is the only option. Many actions could be taken to reduce the anthropogenic impact on the environment. However, since mankind's energy production and, in particular, the combustion of fossil fuels (coal, oil, and natural gas), is the main responsible for the anthropogenic emission of greenhouse gases, the transition towards renewable and carbon-free energy sources is required in the present environmental context to minimise hazardous anthropogenic interference with the natural climate system. Even though such necessity is an obvious 
fact, it is challenging not only for developed countries in which the living standard requires large energy supplies, but also for those developing countries that experience a high population growth.

Among greenhouse gases, carbon dioxide $\left(\mathrm{CO}_{2}\right)$ is considered the most important because, even though its global warming potential (GWP) is much lower than that of other gases, the emissions of $\mathrm{CO}_{2}$ are far more abundant. GWP parameter was developed to compare the global warming impacts of different gases and it is a measure of how much energy the emissions of 1 ton of a gas will absorb over a given period, relative to the emissions of 1 ton of $\mathrm{CO}_{2}$, which is used as the reference. Then, $\mathrm{CO}_{2}$ has a GWP of 1 regardless of the time used, while GWP is 28-36 and 265-298 times that of $\mathrm{CO}_{2}$ for methane $\left(\mathrm{CH}_{4}\right)$ and nitrous oxide $\left(\mathrm{N}_{2} \mathrm{O}\right)$, respectively [1]. Such considerations, that are nowadays central scientific and social concerns, have a long historical background within the research community. Arrhenius was among the first to hypothesise about the impact of $\mathrm{CO}_{2}$ on the Earth's climate [2], but his hypothesis was overlooked until the 1950s [3]. Now, after more than half a century, there is not yet a chemical process able to efficiently clean the growing volumes of $\mathrm{CO}_{2}$ in the atmosphere. Some interesting actions taken so far are related to the production of hydrocarbon fuels by recycling $\mathrm{H}_{2} \mathrm{O}$ and $\mathrm{CO}_{2}$ with renewable energy sources or the $\mathrm{CO}_{2}$ capture and sequestration (CCS) technology [4-7].

In such energy and environmental context, the search for alternative carbon emission-free energy sources is required to avoid further disastrous consequences. Hydrogen $\left(\mathrm{H}_{2}\right)$, a carbon-free fuel, is considered an ideal energy vector. However, the job is far from done and there are still important limitations for the implementation of hydrogen into the global energy scenario. Moreover, $\mathrm{H}_{2}$ is not readily available in nature and, even though it can be generated from renewable sources (i.e. gasification of biomass/biofuels and water splitting), it is mostly produced via steam reforming process, which indeed is not sustainable because it uses fossil fuels and $\mathrm{CO}_{2}$ is produced [8]. Moreover, aside from that, there are also significant limitations related to its difficult storage and delivery [9], as well as safety issues derived from its high flammability and potential explosiveness [10]. A promising alternative to overcome those limitations is the production of $\mathrm{H}_{2}$ from hydrogen carrier molecules. Among them, the so-called Liquid Organic Hydrogen Carriers (LOHC) have recently received great attention as an interesting option to conventional hydrogen technologies, with particular importance for mobile applications. In such molecules, $\mathrm{H}_{2}$ is stored and delivered through reversible hydrogenation and dehydrogenation chemical reactions upon utilisation of suitable catalysts [11]. Among the virtues of LOHC is the fact that they may use the existing infrastructure for fuel [12]. Although the first studies on LOHCs took place in the early 1980s, a renewed interest has emerged in the last years [11,13]. Bessarabov et al. recently summarised the properties of a "good" LOHC as follows [12]: (1) Low melting point $\left(<-30^{\circ} \mathrm{C}\right)$ and high boiling point $\left(>300^{\circ} \mathrm{C}\right)$; (2) High hydrogen storage capacity; (3) Ability to undergo very selective hydrogenation and dehydrogenation reactions for long life cycles of charging and discharging; (4) Toxicological and eco-toxicological safety; (5) Low production costs and good technical availability. Formic acid (methanolic acid, $\mathrm{HCOOH}$, FA), the simplest carboxylic acid $\left(\mathrm{p} K_{\mathrm{a}}=3.75\right)$, is an outstanding LOHC candidate, which not only encompasses most of the features listed above but also, it is a product of the hydrogenation of $\mathrm{CO}_{2}[14,15]$.

The relative moderate hydrogen capacity of $4.4 \mathrm{wt} . \%$ might seem to be its weak point as compared to other LOHC [16]. However, its high density of $1.22 \mathrm{~g} / \mathrm{cm}^{3}$ leads to a volumetric capacity of $53 \mathrm{gH}_{2} / \mathrm{L}$, equivalent to an energy density of $1.77 \mathrm{~kW} \cdot \mathrm{h} / \mathrm{L}$, which is larger than the value of compressed hydrogen at $70 \mathrm{MPa}[9,17]$.

The production of $\mathrm{H}_{2}$ from FA was firstly investigated by Coffey in 1967 [18], but it was not until 2008 when the interest of FA as a LOHC was renewed thanks to the independent investigations carried out by Laurenczy and Beller [19-21]. Along these years, studies dealing with the production of $\mathrm{H}_{2}$ from FA have been carried out by using both, homogeneous and heterogeneous catalysts of diverse composition [22-24]. Due to their significance within the catalytic systems applied to this reaction, 
this paper reviews some of the most representative studies dealing with the decomposition of FA using PdAg-based bimetallic catalysts.

\section{Decomposition of Formic Acid}

The decomposition of FA can follow two pathways according to the following reactions:

$$
\begin{gathered}
\text { Dehydrogenation (decarboxylation): } \mathrm{HCOOH} \leftrightarrow \mathrm{H}_{2}+\mathrm{CO}_{2} ; \Delta \mathrm{G}^{\mathrm{o}}=-32.9 \mathrm{~kJ} \mathrm{~mol}^{-1} \\
\text { Dehydration (decarbonylation): } \mathrm{HCOOH} \leftrightarrow \mathrm{H}_{2} \mathrm{O}+\mathrm{CO} ; \Delta \mathrm{G}^{\mathrm{o}}=-12.4 \mathrm{~kJ} \mathrm{~mol}^{-1}
\end{gathered}
$$

The dehydrogenation path is the target reaction for the production of $\mathrm{H}_{2}$, while dehydration should be avoided due to the poisonous effect of $\mathrm{CO}$. The yield of each reaction could be affected by the reaction conditions (i.e. temperature, concentration, presence of additives, etc.) [25], as well as by the features of the catalytic system used [26].

The decomposition of FA has traditionally been tackled using homogeneous catalysts. Noteworthy in this field are the studies performed by Laurenczy and Beller $[25,27,28]$. However, their obvious limitations in terms of practical application and recovery capabilities have motivated the search for efficient and selective heterogeneous systems able to produce $\mathrm{H}_{2}$ from FA under mild conditions. In this sense, there is an increasing number of publications reporting on the investigation of catalytic systems able to catalyse the reaction while exploring the features of either support or metal active phase. Special mention should be made of those breakthroughs achieved Xu et al. [29-34], Mori et al. [35-46] and Bulushev et al. [47-57].

Most of the heterogeneous catalysts used are based on metal nanoparticles immobilised on supports of diverse nature (i.e. carbon materials, MOF, zeolites, resins, etc.) [23,58,59]. Among the various compositions of the metal active phase analysed so far, Pd nanoparticles are unquestionably the most widely employed since they display both high conversion of FA and selectivity values at moderate temperatures. However, the main weakness of those Pd-based monometallic catalytic systems is the low stability due to quick deactivation by adsorption of reaction intermediates and $\mathrm{CO}$. Such negative effect can be reduced by modification of the properties of Pd nanoparticles by incorporating a second element to form alloy-structures or core-shell Pd-based catalysts. Among those possible compositions, PdAg bimetallic nanoparticles should be highlighted due to their outstanding performance. Furthermore, it is well-known that the final behaviour of the catalysts will not be only given by the active metal phase, but will also depend on the support used, which opens up countless options for tailoring the catalytic properties of the final materials. Herein, some of the most representative approaches followed towards the development of high-performance heterogeneous $\mathrm{PdAg}$ catalysts for the decomposition of FA will be reviewed.

\section{Decomposition of Formic Acid over PdAg Bimetallic Catalysts}

Heterogeneous catalysts formed by bimetallic Pd-based nanoparticles are promising catalysts towards the decomposition of FA. In particular, those systems based on Pd in conjunction with other noble metal have been widely investigated. PdAg-based catalysts deserve the pole position among those bimetallic systems used in this application. They have been proved to be one of the most successful options for attaining high catalytic activity by virtue of the resulting electron-rich Pd species caused by electron transfer from $\mathrm{Ag}$ to Pd in the nanoparticles (the so-called "ligand effect"), which is driven by the net difference in electronegativity (2.2 and 1.9 in Pauling scale, for Pd and $\mathrm{Ag}$, respectively). It has been demonstrated that such electron-rich $\mathrm{Pd}$ species promote the cleavage of the $\mathrm{O}-\mathrm{H}$ bond of FA molecules and favour the formation of formate intermediates. Detailed studies on the reaction mechanisms by kinetic isotope effect (KIE) using $\mathrm{HCOOH}, \mathrm{HCOOD}$, and DCOOH $[35,37]$ were very useful to relate the presence of such electron rich species with the improved catalytic performance resulting from the facilitated $\mathrm{O}-\mathrm{H}$ and $\mathrm{C}-\mathrm{H}$ bond dissociations. Furthermore, studies in which experimental results were combined with theoretical calculations were also useful to relate the presence of electron-rich 
Pd species of bimetallic nanoparticles with the enhancement observed in the final catalytic activity resulting from the favoured O-H and C-H cleavage [38]. Furthermore, lattice contraction of the Pd surface by incorporation of a second element can also modify the adsorption site preference of FA molecules and suppress the formation of $\mathrm{CO}[60,61]$. Aside from the features of the resulting Pd species, an additional benefit of these systems is that $\mathrm{Pd}$ and $\mathrm{Ag}$ can dissolve in each other to form bimetallic alloys with a huge range of compositions [62], which allows the preparation of catalysts with well-defined composition. Promising results have also been achieved with PdAu bimetallic nanoparticles, but the higher cost of Au as compared to Ag hinders its use.

The investigation conducted by Tsang et al. was one of the first studies reporting on the benefits of PdAg catalysts [26]. Three adsorption modes of FA molecules on the surface of the nanoparticles, i.e. monodentate (linear), bidentate (bridging), and multidentate (multilinear), were identified in that study, which were claimed to be prevalent on different sites. According to what they observed, the bridging form was prevalent on terrace sites and it favoured the dehydrogenation path $\left(\mathrm{H}_{2}+\mathrm{CO}_{2}\right)$, while monodentate and multidentate modes were favoured on surface-unsaturated sites and boost the dehydration pathway $\left(\mathrm{H}_{2} \mathrm{O}+\mathrm{CO}\right)$. Based on that observation, Ag-Pd core-shell nanocatalysts were designed and applied. The electronically modified Pd species originated from the charge transfer from $\mathrm{Ag}$ cores were responsible for strengthening the adsorption of bridging modes and for the subsequent enhancement of the catalytic performance. Among other characterization techniques, that study included Fourier transform infrared (FTIR), which was very useful to relate the performance of the catalysts with their properties. The promising results achieved in that study boosted the search for new PdAg-based catalysts. Among the most representative studies are those using carbon materials as supports [58], but some other interesting materials have also been used. In the following sections, representative studies on the decomposition of FA over PdAg-based catalysts supported on diverse materials are addressed.

In order to provide the readers at a glance view of the results achieved in this field, Table 1 lists some of the most representative PdAg-based bimetallic heterogeneous catalysts studied so far for the dehydrogenation of FA, together with the experimental conditions used and TOF values obtained. 
Table 1. PdAg heterogeneous catalytic systems for the dehydrogenation of FA.

\begin{tabular}{|c|c|c|c|c|c|}
\hline Catalysts & Temperature $\left({ }^{\circ} \mathrm{C}\right)$ & Additive & $\begin{array}{l}\text { Concentration } \\
\text { of FA and } \\
\text { Additive (a) }\end{array}$ & TOF $\left(h^{-1}\right)$ & Reference \\
\hline AgPd@MIL-100(Fe) & 25 & - & $1 \mathrm{M}$ & 58 & [63] \\
\hline $\mathrm{PdAg} / \mathrm{C}-\mathrm{FA}$ & 25 & HCOONa & $5 M+5 M$ & $90^{\text {(b) }}$ & [64] \\
\hline $\mathrm{Ag}_{0.1}-\mathrm{Pd}_{0.90} / \mathrm{rGO}$ & 25 & HCOONa & $1 \mathrm{M}+0.67 \mathrm{M}$ & $105^{(b)}$ & [65] \\
\hline C-Pd ${ }_{1} \mathrm{Ag}_{1} \mathrm{BNSs}$ & 25 & HCOONa & $1 \mathrm{M}+0.5 \mathrm{M}$ & 156 & [66] \\
\hline $\mathrm{Ag}_{6} \mathrm{Pd}_{1} / \mathrm{N}-\mathrm{rGO}$ & 25 & - & $5 \mathrm{M}$ & 171 & [67] \\
\hline $\mathrm{PdAg}-\mathrm{MnO}_{\mathrm{x}} / \mathrm{N}-\mathrm{SiO}_{2}$ & 25 & - & $0.25 \mathrm{M}$ & $330^{(b)}$ & [62] \\
\hline AgPd-Hs/G & 25 & HCOONa & $2.5 \mathrm{M}+2.5 \mathrm{M}$ & 333 & [68] \\
\hline $\mathrm{Ag} @ \mathrm{Pd} / \mathrm{N}-\mathrm{GCNT}$ & 25 & - & N/A & 413 & [69] \\
\hline $\mathrm{Ag}_{74} \mathrm{Pd}_{26} /$ graphene & 25 & HCOONa & $0.9 \mathrm{M}+0.1 \mathrm{M}$ & 572 & [70] \\
\hline $\mathrm{PdAg}-\mathrm{MnOx} / \mathrm{N}-\mathrm{SiO}_{2}$ & 30 & - & $0.25 \mathrm{M}$ & $530^{(b)}$ & [62] \\
\hline $\mathrm{AgPd} / \mathrm{MOF}-5-\mathrm{C}$ & 30 & HCOONa & $1.25 \mathrm{M}+3.75 \mathrm{M}$ & 854 & [71] \\
\hline $\mathrm{PdAg}-\mathrm{CeO}_{2} / \mathrm{MC}$ & 30 & $\mathrm{HCOONa}$ & N/A & 2272 & [72] \\
\hline $\mathrm{PdAg}-\mathrm{MnO}_{\mathrm{x}} / \mathrm{N}-\mathrm{SiO}_{2}$ & 35 & - & $0.25 \mathrm{M}$ & $700^{(\mathrm{b})}$ & {$[62]$} \\
\hline $\mathrm{PdAg}-\mathrm{MnO}_{\mathrm{x}} / \mathrm{N}-\mathrm{SiO}_{2}$ & 40 & - & $0.25 \mathrm{M}$ & $1430^{(b)}$ & [62] \\
\hline C-Pd ${ }_{1} \mathrm{Ag}_{1} \mathrm{BNSs}$ & 50 & HCOONa & $1 \mathrm{M}+0.5 \mathrm{M}$ & 378 & [66] \\
\hline $\mathrm{C}-\mathrm{Ag}_{42} \mathrm{Pd}_{58}$ & 50 & - & $1 \mathrm{M}$ & $382^{(b)}$ & [73] \\
\hline $\mathrm{Ag}_{9} \mathrm{Pd}_{91} / \mathrm{g}-\mathrm{C}_{3} \mathrm{~N}_{4}$ & 50 & HCOONa & $1.5 \mathrm{M}+0.5 \mathrm{M}$ & 480 & [74] \\
\hline $\mathrm{Pd}_{50} \mathrm{Ag}_{50} / \mathrm{Fe}_{3} \mathrm{O}_{4} / \mathrm{N}-\mathrm{rGO}$ & 50 & - & $1.33 \mathrm{M}$ & 497 & [75] \\
\hline $\mathrm{Ag}_{0.25} \mathrm{Pd} / \mathrm{WO}_{3}$ & 50 & HCOONa & $0.15 \mathrm{M}+1.2 \mathrm{M}$ & 683 & [76] \\
\hline $\mathrm{Ag}_{10} \mathrm{Pd}_{90} / 0.2 \mathrm{CND} / \mathrm{SBA}-15$ & 50 & HCOONa & $1.5 \mathrm{M}+0.5 \mathrm{M}$ & 893 & [77] \\
\hline $\mathrm{Ag}_{1} \mathrm{Pd}_{9} / \mathrm{SBA}-15$-Amine & 50 & HCOONa & $1.5 \mathrm{M}+0.5 \mathrm{M}$ & 964 & [78] \\
\hline $\mathrm{Ag}_{1} \mathrm{Pd}_{9} @ \mathrm{NPC}$ & 50 & HCOONa & N/A & 3000 & [79] \\
\hline $\mathrm{Ag}_{1} \mathrm{Pd}_{9}-\mathrm{MnO}_{\mathrm{x}} /$ carbonspheres & 50 & HCOOK & $5 \mathrm{M}+15 \mathrm{M}$ & 3558 & [80] \\
\hline $\mathrm{PdAg@ZrO} / \mathrm{C}$ & 50 & HCOOK & $2.5 \mathrm{M}+10 \mathrm{M}$ & 9206 & [81] \\
\hline $\mathrm{Ag}_{74} \mathrm{Pd}_{26} /$ graphene & 60 & HCOONa & $0.9 \mathrm{M}+0.1 \mathrm{M}$ & 572 & [70] \\
\hline $\mathrm{PdAg} @ \mathrm{ZrO}_{2} / \mathrm{C} / \mathrm{rGO}$ & 60 & $\mathrm{HCOONa}$ & $3 \mathrm{M}+7.5 \mathrm{M}$ & 4500 & [32] \\
\hline $\mathrm{Ag}_{1} \mathrm{Pd}_{2} / \mathrm{CN}$ & 75 & - & $2 \mathrm{M}$ & $621^{(b)}$ & [82] \\
\hline $\mathrm{Pd} 1 \mathrm{Ag} 2 / \mathrm{C}(1)$ & 75 & HCOONa & $0.9 \mathrm{M}+0.1 \mathrm{M}$ & $855^{(b)}$ & [43] \\
\hline $\mathrm{PdAg} /$ amine-MSC & 75 & HCOONa & $0.9 \mathrm{M}+0.1 \mathrm{M}$ & 5638 & [15] \\
\hline $\mathrm{Ag}_{18} \mathrm{Pd}_{82} @ \mathrm{ZIF}-8$ & 80 & $\mathrm{HCOONa}$ & N/A & 580 & [83] \\
\hline $\mathrm{Ag}_{20} \mathrm{Pd}_{80} @ \mathrm{MIL}-101$ & 80 & HCOONa & N/A & 848 & [84] \\
\hline $\mathrm{Ag}_{1} \mathrm{Pd}_{4} @ \mathrm{NH}_{2}-\mathrm{UiO}-66$ & 80 & - & $1.25 \mathrm{M}$ & $893^{(b)}$ & [85] \\
\hline AgPd@NPC & 80 & HCOONa & $0.25 \mathrm{M}+0.25 \mathrm{M}$ & 936 & [86] \\
\hline
\end{tabular}

Notes: ${ }^{(a)}$ Expressed as concentration of FA (M) + concentration of additive (M); ${ }^{\text {(b) }}$ Initial TOF values.

\subsection{Carbon-supported PdAg Catalysts}

The success in attaining high-performance catalysts lies, to a large extent, in controlling their final features in terms of composition, morphology, and electronic properties, as well as in finding the properties-activity relationship. For that, diverse and numerous approaches for the control of the features of both metal active phase and catalytic support have been tackled. Among investigated catalytic supports, the role of carbon materials should be highlighted. Their thermal stability, surface resistance in both basic and acidic medium, tunable porosity and surface chemistry, etc., provide great options towards the design of high-performance catalysts while exploring numerous approaches.

$\mathrm{Li}$ et al. investigated the effect of the reducing agent (sodium borohydride (SB), formic acid (FA), ascorbic acid (AA), and hydrogen) utilised during the preparation of catalysts based on $\mathrm{PdAg}$ nanoparticles supported on carbon (PdAg/C-SB, PdAg/C-FA, and $\mathrm{PdAg} / \mathrm{C}-\mathrm{AA}$, and $\mathrm{PdAg} / \mathrm{C}-\mathrm{H}$ ) [64]. It was observed that, while the wet-chemical reduction method provided similar average nanoparticle size in all cases $(\sim 5 \mathrm{~nm})$, larger nanoparticles were attained by using gas-chemical reduction $(7.5 \mathrm{~nm})$. Besides, XPS analysis was used to get information about the surface composition of the nanoparticles. It was found that surface $\mathrm{Pd} / \mathrm{Ag}$ molar ratios followed the order $\mathrm{PdAg} / \mathrm{C}-\mathrm{AA}>\mathrm{PdAg} / \mathrm{C}-\mathrm{FA}>$ $\mathrm{PdAg} / \mathrm{C}-\mathrm{H}>\mathrm{PdAg} / \mathrm{C}-\mathrm{SB}(2.97,2.48,2.34$, and 0.81 , compared to the nominal $\mathrm{Pd} / \mathrm{Ag}$ molar ratio of 1 ), indicating the importance of the reducing agent in controlling the surface composition of PdAg nanoparticles. Among them, the catalyst synthesised by FA-reduction was the most active (initial TOF of $90 \mathrm{~h}^{-1}$ at $25^{\circ} \mathrm{C}$ ), what was claimed to be due to the presence of electron-rich abundant Pd atoms on the surface of the nanoparticles as well as to their alloyed state. Our group also reported on the impact 
of the surface $\mathrm{Pd} / \mathrm{Ag}$ ratio in the final catalytic performance [43]. In that study, we used a promising synthetic strategy based on the preparation of colloidal PVP-capped PdAg nanoparticles through the reduction by solvent method. Firstly, composition-controlled colloidal nanoparticles were prepared by using four different $\mathrm{Pd} / \mathrm{Ag}$ molar ratios (i.e. 1/0.5, 1/1, 1/2, and 1/4) and three PVP/Pd molar ratios $(1 / 1,5 / 1$, and $10 / 1)$ and they were subsequently loaded on activated carbon. The characterisation of the catalysts revealed that the $\mathrm{Pd} / \mathrm{Ag}$ surface ratio (for a given fixed nominal $\mathrm{Pd} / \mathrm{Ag}$ molar ratio in the nanoparticles) was dependent on the amount of PVP used in the synthesis. It was found that, under the conditions used in that synthesis, Pd/Ag ratio decreased with the amount of PVP, which was related to the relative interaction of $\mathrm{Pd}$ and $\mathrm{Ag}$ with the polymer molecules. In that study, the catalyst synthesised with a $\mathrm{Pd} / \mathrm{Ag}$ ratio of $1 / 2$ and $\mathrm{PVP} / \mathrm{Pd}$ of $1 / 1$ was the most active among those studied, achieving an initial TOF value as high as $855 \mathrm{~h}^{-1}$ at $75^{\circ} \mathrm{C}$.

The importance of using composition-controlled monodisperse AgPd nanoparticles in attaining good catalytic performance was also pointed out by Sun et al. [73]. In that study, AgPd nanoparticles with an average size of $2.2 \pm 0.1 \mathrm{~nm}$ were synthesised by co-reduction of metal precursors in oleylamine $(\mathrm{OAm})$, oleic acid $(\mathrm{OA})$ and 1-octadecene (ODE), and they were subsequently loaded on Ketjen carbon for their evaluation as heterogeneous catalysts in the decomposition of FA. The following composition of the nanoparticles was assessed: $\mathrm{Pd}, \mathrm{Ag}_{25} \mathrm{Pd}_{75}, \mathrm{Ag}_{42} \mathrm{Pd}_{58}, \mathrm{Ag}_{52} \mathrm{Pd}_{48}, \mathrm{Ag}_{60} \mathrm{Pd}_{40}, \mathrm{Ag}_{80} \mathrm{Pd}_{20}$, and $\mathrm{Ag}$. Control of the nanoparticle size was achieved by means of modifying the content of $\mathrm{OA}$ used in the synthesis. High total metal contents were used for the synthesis of the supported catalysts (i.e. $17 \mathrm{wt}$ \% $\mathrm{AgPd}, 19$ wt. \% Pd, and 18 wt. \% Ag, for C-AgPd, C-Pd, and C-Ag catalysts, respectively). Except for the sample with larger Ag content, all bimetallic systems displayed enhanced performance with respect to the monometallic counterpart, which was particularly important in C- $\mathrm{Ag}_{42} \mathrm{Pd}_{58}$ (initial TOF of $382 \mathrm{~h}^{-1}$ at $\left.50^{\circ} \mathrm{C}\right)$. Such enhancement was attributed to the small size of the nanoparticle $(2.2 \pm 0.1$ and $4.5 \pm 0.2 \mathrm{~nm}$, for AgPd and Pd nanoparticles, respectively) and the synergistic Ag-Pd effect in the alloy catalysts. An aspect to highlight of that study is that the reusability tests revealed that around $90 \%$ of the initial activity of the catalysts was preserved after four consecutive catalytic runs.

Cheng et al. also investigated the performance of monodisperse PdAg-based bimetallic catalysts for the decomposition of FA by following a similar synthetic strategy [70]. In that case, AgPd nanoparticles (average nanoparticle size of $3.0 \pm 0.2 \mathrm{~nm}$ ) were prepared by co-reduction of $\mathrm{AgNO}_{3}$ and $\mathrm{Pd}(\mathrm{acac})_{2}$ in $\mathrm{OAm}, \mathrm{OA}$ and $\mathrm{ODE}$, and using tert-butylamine borane $\left(\mathrm{BH}_{3} \cdot \mathrm{C}_{4} \mathrm{H}_{11} \mathrm{~N}, \mathrm{TBB}\right)$ as a reducing agent. The as-synthesised nanoparticles were subsequently loaded on graphene to obtain AgPd/graphene catalysts with various compositions of the nanoparticles $\left(\mathrm{Ag}_{92} \mathrm{Pd}_{8} / g r a p h e n e, \mathrm{Ag}_{86} \mathrm{Pd}_{14} / \mathrm{graphene}\right.$ $\mathrm{Ag}_{74} \mathrm{Pd}_{26} /$ graphene, $\mathrm{Ag}_{51} \mathrm{Pd}_{49} /$ graphene, and $\mathrm{Ag}_{41} \mathrm{Pd}_{59} /$ graphene). Monometallic counterpart catalysts were also synthesised as references. The formation of alloy nanoparticles was confirmed by high-resolution TEM (HRTEM) analysis and UV-vis spectra, in which the surface plasmon resonance (SPR) of Ag located at $427 \mathrm{~nm}$ decreased considerably upon alloying with Pd. Among those compositions assessed, $\mathrm{Ag}_{74} \mathrm{Pd}_{26} /$ graphene displayed the highest TOF value $\left(572 \mathrm{~h}^{-1}\right.$, at room temperature). In addition, a catalyst with the same composition of the nanoparticles and supported on Ketjen carbon was also evaluated and it showed inferior performance than $\mathrm{Ag}_{74} \mathrm{Pd}_{26} /$ graphene, which indicated the positive role of graphene as a 2D support in promoting the mass transport and electron transfer. Furthermore, it was also observed that the reducing agent used (TBB) was crucial in attaining monodisperse AgPd nanoparticles. The use of different reducing agents (i.e. triethylamine borane (TEB) or methylamine borane (MeAB)) resulted in larger nanoparticles and the subsequent activity decay. It that case, as in most of the catalysts reported so far for the decomposition of FA, the reusability was shown to be the critical point to be enhanced.

Apart from the reducing agent used in the synthesis and the presence of capping agents, the selection of suitable catalytic support is a well-known option for attaining small and well-dispersed metal nanoparticles. For instance, Jiang et al. selected reduced graphene oxide (rGO) as excellent support and powerful dispersion agent of bimetallic $\mathrm{AgPd}$ nanoparticles prepared by co-reduction of $\mathrm{AgNO}_{3}$ and $\mathrm{Na}_{2} \mathrm{PdCl}_{4}$ with $\mathrm{NaBH}_{4}$ [65]. TEM analysis revealed that the supported $\mathrm{Ag}_{0.1} \mathrm{Pd}_{0.9}$ 
nanoparticles had an average size of $6 \mathrm{~nm}$, while severe aggregation was found for the counterpart free-nanoparticles. It was claimed that oxygen functional groups present in GO (i.e. carboxylic, carbonyl, and hydroxyl) were pivotal for controlling the size of the nanoparticles. In addition, XPS analysis revealed the strong metal-support interaction existing in the final catalysts. As results of those features, $\mathrm{Ag}_{0.1} \mathrm{Pd}_{0.9} / \mathrm{rGO}$ generated a large volume of gas $\left(\mathrm{H}_{2}\right.$ and $\left.\mathrm{CO}_{2}\right)$ and an initial TOF of $105.2 \mathrm{~h}^{-1}$ at $25^{\circ} \mathrm{C}$, which was much larger than that of the free nanoparticles counterpart. The role of the support was confirmed by evaluating the catalytic performance of a physical mixture of rGO and $\mathrm{Ag}_{0.1} \mathrm{Pd}_{0.9}$. The decayed activity observed in that case was indicative of the important synergistic effect between support and nanoparticles and its role in attaining well-dispersed nanoparticles with better ability for boosting the production of $\mathrm{H}_{2}$ from FA.

In an attempt to explore the behaviour of new carbon materials, Wang et al. investigated the utilisation of metal-organic framework (MOF) derived porous carbon as support of AgPd catalysts [71]. In that case, MOF- 5 was used as precursor and template for the synthesis of nanoporous carbon via direct carbonisation at different temperatures (i.e. 700, 800, 900, $1000^{\circ} \mathrm{C}$ ), and $\mathrm{AgPd}$ nanoparticles were subsequently deposited from $\mathrm{AgNO}_{3}$ and $\mathrm{H}_{2} \mathrm{PdCl}_{4}$. Nanoparticles with fixed composition were supported on carbon obtained from the calcination of MOF-5-C at different temperatures (catalysts denoted as $\mathrm{Ag}_{3} \mathrm{Pd}_{12} / \mathrm{MOF}-5-\mathrm{C}-700, \quad \mathrm{Ag}_{3} \mathrm{Pd}_{12} / \mathrm{MOF}-5-\mathrm{C}-800, \mathrm{Ag}_{3} \mathrm{Pd}_{12} / \mathrm{MOF}-5-\mathrm{C}-1000$ ). Furthermore, a carbon-supported catalyst using Vulcan XC-72 $\left(\mathrm{Ag}_{3} \mathrm{Pd}_{12} / \mathrm{XC}-72\right)$ and catalysts using MOF-5-C-900 with various $\mathrm{Ag} / \mathrm{Pd}$ ratios, were also prepared for comparison purposes ( $\mathrm{Pd}_{15} / \mathrm{MOF}-5-\mathrm{C}-900, \mathrm{Ag}_{6} \mathrm{Pd}_{9} / \mathrm{MOF}-5-\mathrm{C}-900$, and $\left.\mathrm{Ag}_{15} / \mathrm{MOF}-5-\mathrm{C}-900\right)$, being the total metal loading of $15 \mathrm{wt} . \%$ in all cases. Catalyst $\mathrm{Ag}_{3} \mathrm{Pd}_{12} / \mathrm{MOF}-5-\mathrm{C}-900$ displayed the best performance among the investigated catalysts, with an initial TOF value of $854 \mathrm{~h}^{-1}$ at $30{ }^{\circ} \mathrm{C}$. The results of the catalytic tests together with the characterisation of the samples make the authors of that study claim that the improved performance displayed by $\mathrm{Ag}_{3} \mathrm{Pd}_{12} / \mathrm{MOF}-5-\mathrm{C}-900$ as compared to other samples was due to the composition of the nanoparticles in that sample (i.e. alloy PdAg and monometallic $\mathrm{Pd}^{0}$ and $\mathrm{Ag}^{0}$ ) and their small size and good dispersion on the support. In addition, the role of sodium formate (SF) in the final catalytic activity was also studied by using various FA/SF ratios in the reaction medium (i.e. $1 / 1,1 / 2,1 / 3$, and 1/4). It was postulated that the presence of SF increased the likelihood of contact between metal active sites and formate ions, which would, therefore, accelerate the kinetics of the FA decomposition reaction. A similar conclusion had previously been extracted by Cai et al. [87], who demonstrated that hydrogen produced by direct formate hydrolysis $\left(\mathrm{HCOO}^{-}+\mathrm{H}_{2} \mathrm{O} \rightarrow \mathrm{H}_{2}+\mathrm{HCO}_{3}^{-}\right)$ was negligible (while using only formate ion in absence of FA in the reaction mixture), while the presence of formate greatly promoted the dehydrogenation of FA in FA/SF mixtures. Such beneficial effect was claimed to be due to the induction of a favourable adsorption orientation of FA on the catalysts to favour the dehydrogenation pathway in presence of formate ions. Moreover, the role of formate as reaction intermediate was also mentioned.

As for the morphology of the metal active phase, most of the studies reports on the use of sphere-shaped or cubo-octahedral "solid" nanoparticles with a relative low ratio of metal surface atoms in the total nanostructure. Decreasing the nanoparticle size is a well-known strategy for increasing the surface atoms exposed in the nanoparticles, but such an approach does not always lead to enhanced catalytic performances [88]. In some cases, the higher reactivity of smaller nanoparticles favours the adsorption of reaction intermediates, which leads to space exclusion and block the active sites, ultimately resulting in poorer catalytic activities as compared to less reactive larger nanoparticles [88]. Some other investigations are focused on increasing the ratio of surface-active sites by constructing other nanostructures. For example, Chen et al. reported on the preparation of graphene-supported AgPd hollow nanoparticles [68]. A one-pot wet-chemical co-reduction of GO and metal precursors was used in that case using trisodium citrate dihydrate as the stabiliser and L-ascorbic acid (L-AA) as the reducing agent (see Figure 1). Such a synthetic approach afforded the development of sphere-shaped hollow nanoparticles with a thin wall of $5 \mathrm{~nm}$ and an average size of $18 \mathrm{~nm}$, which were well-dispersed on the surface of the catalyst (catalysts denoted as $\mathrm{AgPd}-\mathrm{Hs} / \mathrm{G}$ ). $\mathrm{Pd} / \mathrm{G}$ and $\mathrm{AgPd} / \mathrm{C}$ catalysts were also 
prepared for comparison purposes in that study. XPS analysis revealed the existence of $\mathrm{Pd}^{0}, \mathrm{PdO}$ and $\mathrm{Ag}^{0}$ in $\mathrm{AgPd}-\mathrm{Hs} / \mathrm{G}$. It was also observed that $\mathrm{AgPd}$ nanoparticles acted as nanoscaled spacers by increasing the interlayer spacing between graphene sheets and avoiding graphene layers stacking. In addition, it was also demonstrated that the formation of $\mathrm{AgPd}$ alloy nanoparticles was assisted by $\mathrm{GO}$ and the use of additives such as trisodium citrate dihydrate since such structures were not formed upon utilisation of other supports or in absence of additives. Regarding the catalytic activity, it was observed that $\mathrm{AgPd}-\mathrm{Hs} / \mathrm{G}$ generated as much as twice of the volume of gas generated by $\mathrm{AgPd} / \mathrm{C}$, which further confirmed the suitability of graphene as catalytic support in the present application. Besides, the importance of the hollow structure, in which most of the atoms are located on the surface of the nanoparticles, was also evidenced by comparison with a $\mathrm{AgPd} / \mathrm{G}$ counterpart catalyst.

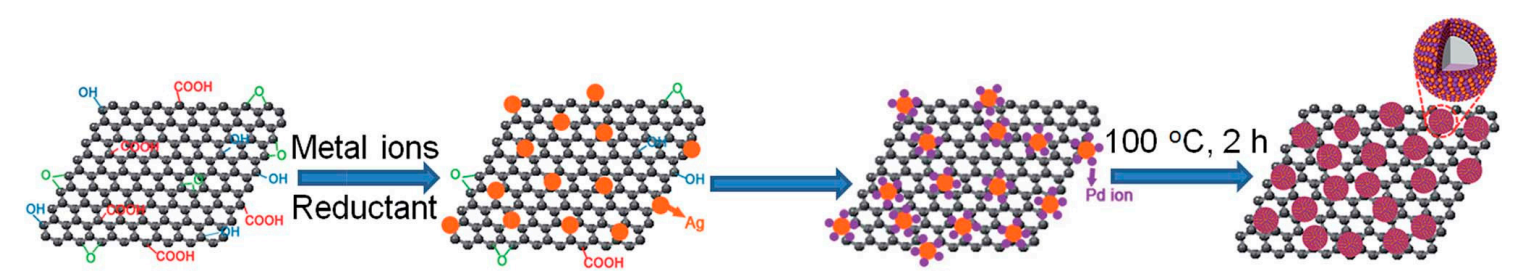

Figure 1. Schematic illustration for the preparation of AgPd-Hs/G. The preparation involves the redox reaction between the Pd ions and Ag nanoparticles. Reprinted with permission from [68].

Zheng et al. studied the synergetic effects of PdAg nanoparticles in the decomposition of FA by using two-dimensional ultrathin PdAg bimetallic nanosheets as model catalysts [66]. Such structures were selected to study the Pd-Ag synergic effect because, as in the case of hollow bimetallic nanostructures previously mentioned [68], they have a high fraction of active sites on the surface. Furthermore, the relation between the structure and the catalytic performance displayed by the nanosheets can be easily analysed due to the presence of a simple type of active sites. The preparation of PdAg bimetallic nanosheets (PdAg BNSs) was carried out in two steps.

Firstly, Pd NSs with hexagonal morphology were obtained from $\mathrm{Pd}(\mathrm{acac})_{2}$, and after that, different contents of $\mathrm{Ag}$ (i.e. Pd/Ag ratios of 2/1, 1/1, 1/2, and 1/10) were chemically deposited on the as-prepared $\mathrm{Pd} \mathrm{NSs}$ by using $\mathrm{AgNO}_{3}$ and sodium citrate as metal precursor and reducing agent, respectively. The role of citrate in the synthesis was a key aspect for attaining alloy structures, due to its strong coordinating ability with $\mathrm{Ag}^{+}$and $\mathrm{Pd}^{2+}$. The resulting PdAg BNSs preserved hexagonal morphology, but their thickness increased (as compared to Pd NSs) with the Ag content. After that, the obtained PdAg BNSs were loaded onto Vulcan XC-72 carbon to have a final Pd content of $5 \mathrm{wt} . \%$ in all cases (catalysts denoted as C-PdAg). In addition, monometallic Pd NSs (with a thickness of $1.8 \mathrm{~nm}$ and an average diameter of $85 \mathrm{~nm}$ ) were also loaded on carbon (C-Pd) to check their activity in the reaction under evaluation. It was observed that C-Pd displayed a very poor activity and durability, which was attributed to the adsorption of $\mathrm{CO}$ produced via dehydration reaction on $\mathrm{Pd}$ (111) surface. The results of the catalytic performance achieved by C-PdAg catalysts is depicted in Figure 2. As can be seen in Figure 2a,b, the catalytic activity strongly depended on the composition of the catalysts, being optimum for C-PdAg with a ratio of 1/1. Further addition of Ag caused a marked activity decay due to excessive coverage of $\mathrm{Pd}$ active sites. The prominent catalytic activity of that sample was explained in terms of electronic promotion of $\mathrm{Pd}$ by $\mathrm{Ag}$ in the bimetallic structure. Besides, the activation energy of that catalyst was determined from experiments done at different temperatures (Figure 2c,d). Cyclic voltammograms (CV), CO stripping measurements and in-situ FTIR analysis helped to correlate the catalytic activity with the ability against $\mathrm{CO}$ poisoning. 

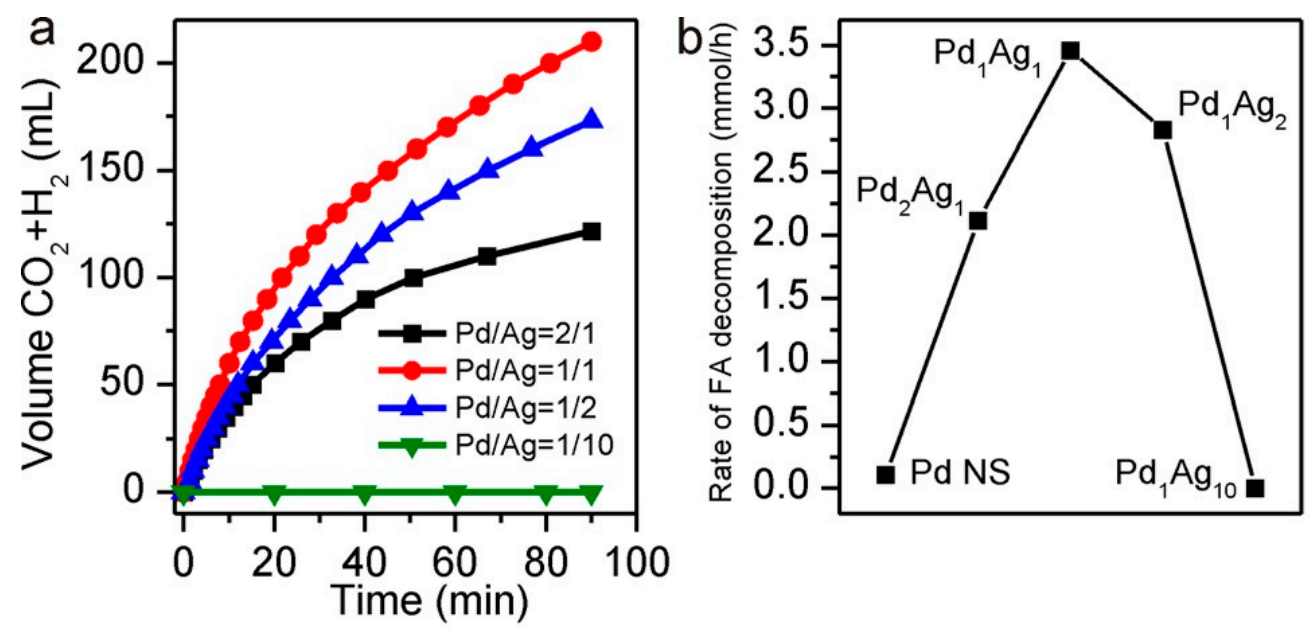

C
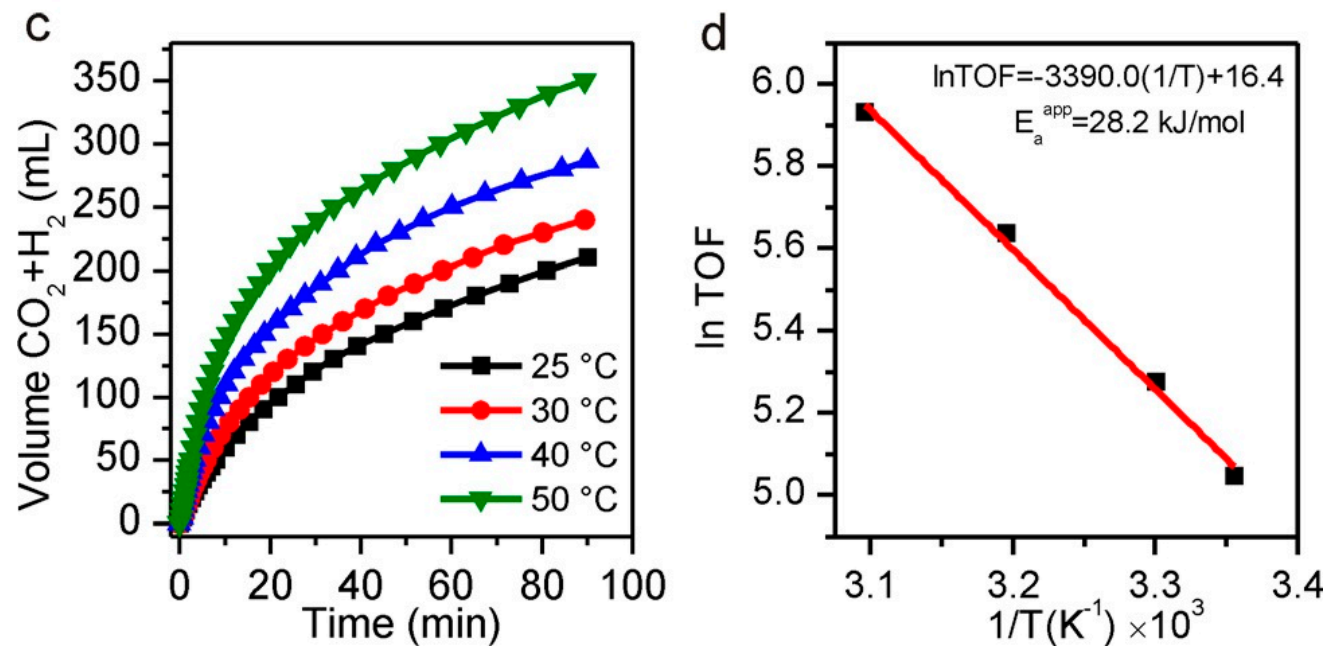

Figure 2. (a) Plots of the volume of generated gases $\left(\mathrm{CO}_{2}+\mathrm{H}_{2}\right)$ versus time from $10 \mathrm{~mL}$ solution of $1 \mathrm{M}$ $\mathrm{FA}+0.5 \mathrm{M} \mathrm{SF}$ in the presence of $50 \mathrm{mg}$ C-PdAg BNSs with different $\mathrm{Ag} / \mathrm{Pd}$ ratios (5 wt. \% Pd for all catalysts) at $25{ }^{\circ} \mathrm{C}$ under ambient atmosphere. (b) Rate of FA decomposition catalysed by different C-PdAg BNSs. (c) Plots of the volume of generated gases $\left(\mathrm{CO}_{2}+\mathrm{H}_{2}\right)$ catalysed by C-Pd $\mathrm{Ag}_{1} \mathrm{BNSs}$ under different temperatures. (d) Arrhenius plot (ln (TOF) vs.1/T). Reprinted with permission from [66].

\subsection{N-Doped Carbon-based PdAg Catalysts}

The utilisation of "functional support" has widely been reported as an interesting option for achieving catalysts with tailored properties. As for the catalysts based on monometallic Pd nanoparticles, it was observed that the addition of nitrogen atoms into the carbon matrix promoted the electrical conductivity of the resulting material and serves as sites for the immobilisation of metal through strengthening the metal-support interaction. Furthermore, it has also been noted that, due to their basic character, nitrogen atoms can actively participate in the dehydrogenation of FA [16,53,57,89-91]. Then, due to the positive role of the addition of nitrogen functional groups in the support, it has also been a very fruitfully investigated strategy for the enhancement of the final performance of PdAg-based catalysts while considering supports of diverse nature.

Qui et al. demonstrated the suitability of nitrogen-modified carbon material as support of PdAg catalysts for the decomposition of FA [67]. In that case, nitrogen modified reduced graphene oxide (N-rGO) was used and catalysts with diverse nanoparticle compositions (i.e. $\mathrm{Pd}_{2} \mathrm{Ag}_{1} / \mathrm{N}-\mathrm{rGO}$, $\mathrm{Pd}_{1} \mathrm{Ag}_{1} / \mathrm{N}-\mathrm{rGO}, \mathrm{Pd}_{1} \mathrm{Ag}_{2} / \mathrm{N}-\mathrm{rGO}, \mathrm{Pd}_{1} \mathrm{Ag}_{4} / \mathrm{N}-\mathrm{rGO}, \mathrm{Pd}_{1} \mathrm{Ag}_{6} / \mathrm{N}-\mathrm{rGO}, \mathrm{Pd}_{1} \mathrm{Ag}_{8} / \mathrm{N}-\mathrm{rGO}$ ) were prepared from $\mathrm{AgNO}_{3}$ and $\mathrm{Pd}\left(\mathrm{NO}_{3}\right)_{2}$. The analysis of the characterisation results suggested that $\mathrm{Pd}$ atoms were more prone to be at the surface of the nanoparticles, which was not explained by the standard 
electrode potential of the pairs $\mathrm{Pd}^{2+} / \mathrm{Pd}$ and $\mathrm{Ag}^{+} / \mathrm{Ag}(0.951 \mathrm{~V}$ and $0.800 \mathrm{~V}$, vs. SHE, respectively). Then, such Pd surface enrichment was related to the reducing ability of N-rGO for pre-forming Ag particles. Interestingly, it was shown in that study that low Pd-loading catalyst $\left(\mathrm{Pd}_{1} \mathrm{Ag}_{6} / \mathrm{N}-\mathrm{rGO}\right)$ was able to achieve a relatively high TOF value $\left(171 \mathrm{~h}^{-1}\right)$ at room temperature. Etemadi el at. reported on the utilisation of Ag-core Pd-shell nanoparticles supported on nitrogen-doped graphene carbon nanotube aerogel (Ag@Pd/N-GCNT) [69]. In that study graphene and CNTs were integrated into a hybrid aerogel, which was subsequently loaded with $\mathrm{Ag}$ and Pd in consecutive steps, to obtain controlled composition core-shell nanoparticles (i.e. $\mathrm{Ag}_{1} @ \mathrm{Pd}_{2} / \mathrm{N}-\mathrm{GCNT}, \mathrm{Ag}_{1} @ \mathrm{Pd}_{1} / \mathrm{N}-\mathrm{GCNT}, \mathrm{Ag}_{2} @ \mathrm{Pd}_{1} / \mathrm{N}-\mathrm{GCNT}, \mathrm{Ag} / \mathrm{N}-\mathrm{GCNT}$, and $\mathrm{Pd} / \mathrm{N}-\mathrm{GCNT}$ ). It was observed that, aside from the N-sites, graphene carbon nanotube aerogel had additional stabilisation points for the nanoparticles that prevent their aggregation. In that case, catalysts with a $\mathrm{Ag} / \mathrm{Pd}$ molar ratio $1 / 1$ displayed the best activity among the investigated composition, with a TOF value of $413 \mathrm{~h}^{-1}$ at $25^{\circ} \mathrm{C}$.

Wang et al. analysed the catalytic performance of AgPd nanoparticles loaded on $\mathrm{N}$-doped porous carbon synthesised from the carbonisation of a zeolitic imidazolate framework (ZIF-8) at various temperatures (i.e. 800,900 , and $1000{ }^{\circ} \mathrm{C}$ ) [86]. The schematic illustration of the steps followed in the preparation of AgPd-based catalysts supported on nanoporous carbon (AgPd@NPC) is depicted in Figure 6.

The analysis of the composition of the catalysts indicated that the final $\mathrm{Zn}$ content decreased as the carbonisation temperature increased $(7.49,1.69$, and $0.55 \mathrm{wt} . \%$ for nanoporous carbon obtained at 800, 900 and $1000^{\circ} \mathrm{C}$, respectively). XPS analysis demonstrated that there was an important interaction and electron transfer between $\mathrm{Zn}$ and alloy AgPd nanoparticles. The catalytic performance was assessed while checking the effect of both the composition of the nanoparticles and the temperature used in the carbonisation of carbon precursor. It was observed that both parameters played key roles. On the one hand, it was shown that, for a fixed carbonisation temperature, the catalyst with a composition of $\mathrm{Ag}_{1} \mathrm{Pd}_{4}$ displayed the most promising behaviour. On the other hand, the comparison of catalysts with $\mathrm{Ag}_{1} \mathrm{Pd}_{4}$ and loaded on carbon prepared at different temperatures revealed that the nanoporous carbon prepared at $900{ }^{\circ} \mathrm{C}$ was most suitable in this particular case. As a consequence of the optimisation of both parameters, $\mathrm{Ag}_{1} \mathrm{Pd}_{4} @ \mathrm{ZIF}-\mathrm{C}$ (900) catalyst displayed the best performance among those investigated with a $100 \%$ of selectivity and a TOF value of $936 \mathrm{~h}^{-1}$ at $80^{\circ} \mathrm{C}$. Furthermore, that catalyst showed outstanding recyclability during five consecutive reaction runs.

Yamashita et al. also reported on the investigation of PdAg catalysts supported on N-containing carbon material [15]. Their study was centred in the development of efficient dual catalysts towards the reversible delivery/storage of $\mathrm{H}_{2}$ in $\mathrm{FA} / \mathrm{CO}_{2}$. For that, $\mathrm{PdAg}$ nanoparticles loaded on phenylamine-functionalised mesoporous carbon ( $\mathrm{PdAg} / \mathrm{amine}-\mathrm{MSC}$ ) were synthesised from $\mathrm{Pd}\left(\mathrm{NO}_{3}\right)_{2}$ and $\mathrm{AgNO}_{3}$. The experimental approach followed in that study produced amine-MSC with a concentration of amine groups of around $0.57 \mathrm{mmol} \mathrm{g}^{-1}$. Reference samples were also prepared (Pd/MSC, Pd/amine-MSC, and PdAg/MSC). The characterisation of PdAg/amine-MSC revealed the presence of bimetallic alloy nanoparticles with an average size of $1.2 \mathrm{~nm}$ and homogeneous distribution of both elements. It was also suggested that metal nanoparticles were loaded near the amine groups and that such functionalisation favoured the formation of Ag-core rich and Pd-shell rich nanoparticles. As a result of such features, $\mathrm{PdAg} / \mathrm{amine}-\mathrm{MSC}$ showed an excellent catalytic activity with a TOF value as high as $5638 \mathrm{~h}^{-1}$ at $75^{\circ} \mathrm{C}$, which was much superior to that value obtained for the reference catalysts. The role of phenylamine in the catalytic performance was investigated by DFT calculations, which revealed that both reaction steps, $\mathrm{O}-\mathrm{H}$ dissociation and $\mathrm{H}_{2}$ desorption were boosted by such N-groups.

Wang et al. recently addressed a study in which the importance of the support morphology was investigated by preparing AgPd catalysts supported on $\mathrm{N}$-decorated porous carbon nanosheets prepared from glucose and $g-\mathrm{C}_{3} \mathrm{~N}_{4}$ by a template-induced strategy [79]. The lamellar structure obtained served as support of $\mathrm{AgPd}$ nanoparticles with compositions of $\mathrm{Ag}_{1} \mathrm{Pd}_{9} / \mathrm{NPC}, \mathrm{Ag}_{3} \mathrm{Pd}_{7} / \mathrm{NPC}$, $\mathrm{Ag}_{5} \mathrm{Pd}_{5} / \mathrm{NPC}, \mathrm{Ag}_{7} \mathrm{Pd}_{3} / \mathrm{NPC}, \mathrm{Ag}_{9} \mathrm{Pd}_{1} / \mathrm{NPC}, \mathrm{Pd} / \mathrm{NPC}$, and $\mathrm{Ag} / \mathrm{NPC}$. Among them, $\mathrm{Ag}_{1} \mathrm{Pd}_{9} / \mathrm{NPC}$ was 
the most active catalyst. It was observed that the amount of template $\left(g-\mathrm{C}_{3} \mathrm{~N}_{4}\right)$ used in the synthesis did not have any effect on the catalysis of the resulting materials, while the morphology and surface properties of the support (which were varied by controlling the synthesis conditions) had a pivotal role in the final performance of the catalysts.

\subsection{Metal Oxide-containing Carbon-based PdAg Catalysts}

The presence of metal oxides can provide a basic character to carbon-supported catalysts. Also, it is known that certain metal oxides may enhance the final catalytic performance by serving as sites for the preferable adsorption of $\mathrm{CO}$, and/or modifying the electronic properties of the metal nanoparticles.

$\mathrm{Xu}^{\prime}$ 's group reported on the utilisation of multicomponent PdAg catalysts with $\mathrm{rGO}$, in which the presence of a metal oxide benefited the formation of electron-rich PdAg species [32]. In that case, zirconia/porous carbon/reduced graphene oxide $\left(\mathrm{ZrO}_{2} / \mathrm{C} / \mathrm{rGO}\right)$ nanocomposites derived from $\mathrm{MOF}$ (UiO-66)/GO were synthesised by using the experimental approach illustrated in Figure 3. The effect of the composition of the nanoparticles was assessed by preparing catalysts with different $\mathrm{Pd}$ to $\mathrm{Ag}$ molar ratios (i.e. $\mathrm{Pd}_{0.9} \mathrm{Ag}_{0.1}, \mathrm{Pd}_{0.7} \mathrm{Ag}_{0.3}, \mathrm{Pd}_{0.6} \mathrm{Ag}_{0.4}, \mathrm{Pd}_{0.5} \mathrm{Ag}_{0.5}, \mathrm{Pd}_{0.4} \mathrm{Ag}_{0.4}$, and $\mathrm{Pd}_{0.2} \mathrm{Ag}_{0.8}$ ), as well as the monometallic counterparts. The evaluation of the catalytic activity at $60{ }^{\circ} \mathrm{C}$ suggested that, under the experimental conditions used in that study, the optimum composition of the nanoparticles was $\mathrm{Pd}_{0.6} \mathrm{Ag}_{0.4}$ and the further addition of $\mathrm{Pd}$ resulted in a lower activity. The best-performing catalysts among the investigated $\left(\mathrm{Pd}_{0.6} \mathrm{Ag}_{0.4} @ \mathrm{ZrO}_{2} / \mathrm{C} / \mathrm{rGO}\right)$ showed a TOF value of $4500 \mathrm{~h}^{-1}$ (at $\left.60{ }^{\circ} \mathrm{C}\right)$ and $100 \%$ selectivity towards the dehydrogenation reaction. Such outstanding performance was ascribed to the small size and high dispersion of the nanoparticles as well as the electron-rich PdAg surface species.

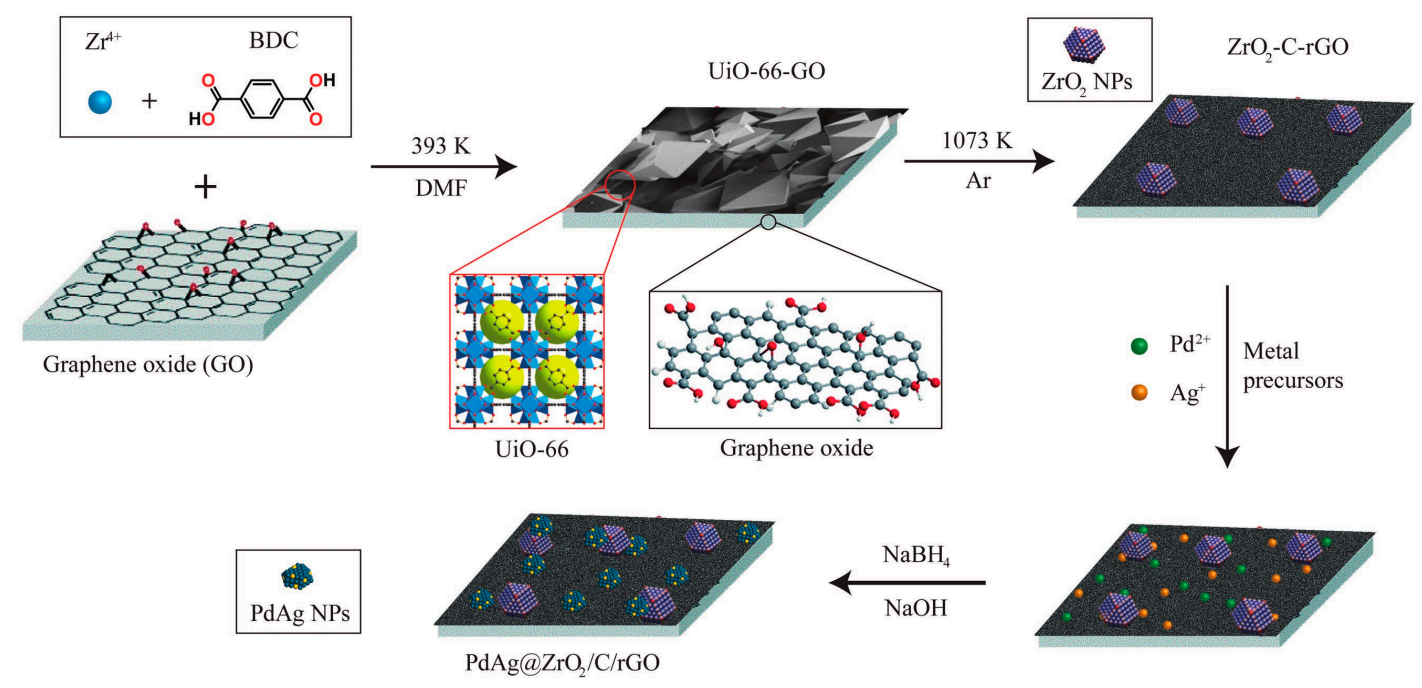

Figure 3. Schematic illustration for preparation of the PdAg@ $\mathrm{ZrO}_{2} / \mathrm{C} / \mathrm{rGO}$ nanocatalyst. Reprinted with permission from [32].

Following Xu's work [32], Wang et al. studied the performance of PdAg catalysts supported on $\mathrm{N}$-doped porous carbon embedded $\mathrm{ZrO}_{2}$ nanohybrids obtained from $\mathrm{UiO}$ materials after calcination at temperatures ranging from 700 to $1000{ }^{\circ} \mathrm{C}\left(\mathrm{PdAg} @ \mathrm{ZrO}_{2} / \mathrm{C}\right)$ [81]. XRD analysis was used to determine the phase of zirconia present for each synthesis temperature (i.e. amorphous at $700{ }^{\circ} \mathrm{C}$, and monoclinic $\left(\mathrm{m}-\mathrm{ZrO}_{2}\right)$ and tetragonal $\left(\mathrm{t}-\mathrm{ZrO}_{2}\right)$ at higher temperatures). Additional catalysts with various supports ( $\mathrm{t}-\mathrm{ZrO}$, carbon-free $\mathrm{ZrO}_{2}$, pure carbon black, $\mathrm{N}$-doped porous carbon, and $\mathrm{N}$-free $\mathrm{ZrO}_{2} / \mathrm{C}$ ) were prepared to get insight into the role of $\mathrm{ZrO}_{2}$. Detailed characterisation of the catalysts revealed that there were oxygen vacancies in $\mathrm{ZrO}_{2}$, which were formed due to the oxygen transfer from $\mathrm{ZrO}_{2}$ to $\mathrm{N}$-carbon. Furthermore, the relative basicity of the catalysts was also investigated, and the results obtained indicated that the catalysts prepared by carbonisation at $900^{\circ} \mathrm{C}$ had the largest content of basic sites. Such observation was consistent with its better catalytic performance as compared to the rest 
of the samples under evaluation. The enhanced activity displayed by $\mathrm{ZrO}_{2}$-containing catalysts was ascribed to the role of that oxide in both modifying the electronic properties of metal nanoparticles by creating surface electron-rich PdAg nanoparticles, as well as in providing basicity to the final materials.

Recently, Lu et al. designed carbon-supported metal oxide-containing PdAg catalysts with outstanding catalytic performance [72]. In that case, the advantage of the basic character of $\mathrm{CeO}_{2}$ and interface properties optimisation by the strong coordination between that oxide and metals was taken into account to fabricate efficient $\mathrm{PdAg}-\mathrm{CeO}_{2}$ catalysts supported on mesoporous carbon ( $\left.\mathrm{PdAg}-\mathrm{CeO}_{2} / \mathrm{MC}\right)$. The mesoporosity of the selected carbon was claimed to benefit the mass transfer process and increase the reaction kinetics. Catalysts were obtained from a surfactant-free co-reduction approach using $\mathrm{Na}_{2} \mathrm{PdCl}_{4}, \mathrm{AgNO}_{3}$, and $\mathrm{Ce}\left(\mathrm{NO}_{3}\right)_{3} \cdot 6 \mathrm{H}_{2} \mathrm{O}$, as metal precursors, and $\mathrm{NaBH}_{4}$ as a reducing agent. Both $\mathrm{Pd}$ to $\mathrm{Ag}$ ratio (i.e. $\mathrm{Pd}_{0.9} \mathrm{Ag}_{0.1}, \mathrm{Pd}_{0.7} \mathrm{Ag}_{0.3}, \mathrm{Pd}_{0.4} \mathrm{Ag}_{0.4}$, and $\mathrm{Pd}_{0.5} \mathrm{Ag}_{0.5}$ ) and $\mathrm{CeO}_{2}$ to carbon ratio were varied. In addition, carbon-free and $\mathrm{CeO}_{2}$-free catalysts were also assessed as reference materials. According to the characterisation results, $\mathrm{PdAg}-\mathrm{CeO}_{2}$ composite was formed on the surface of the carbon material. XPS analysis confirmed the presence of $\mathrm{Ce}^{3+}$, revealing the formation of oxygen vacancies that serve as defects to coordinate with the carbon support and metals. Furthermore, the comparison with $\mathrm{CeO}_{2}$-free catalyst revealed that the presence of such oxide decreased the crystallinity of PdAg nanoparticles, thus resulting in the formation of more active site on the surface of the nanoparticles. The resulting catalysts were assessed towards the dehydrogenation of FA using sodium formate (SF, HCOONa) as an additive (see Figure 4).
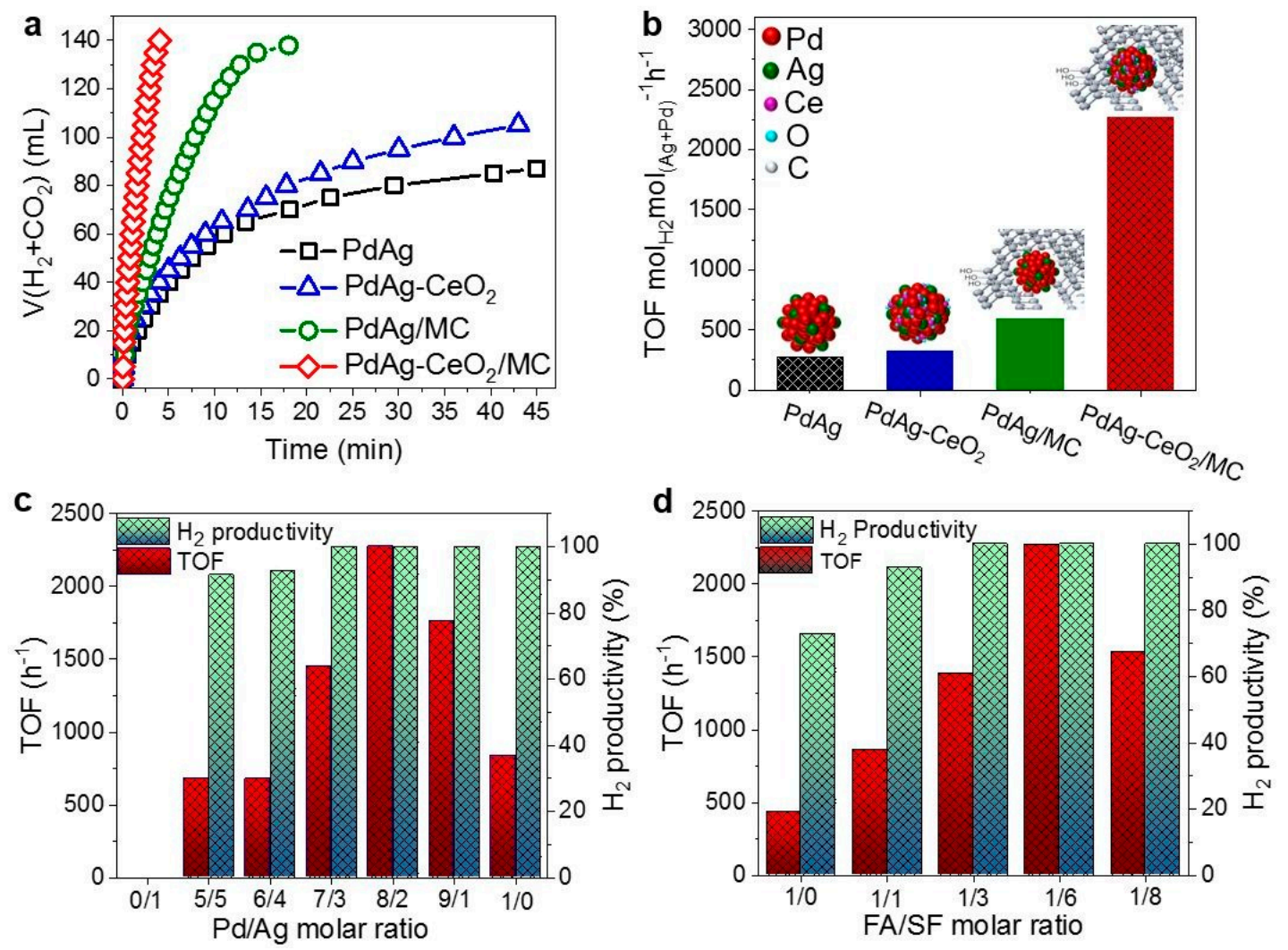

Figure 4. (a) Volume of the generated gas $\left(\mathrm{H}_{2}+\mathrm{CO}_{2}\right)$ versus time and (b) the corresponding TOF values for FA dehydrogenation in a FA-SF solution at $30^{\circ} \mathrm{C}$ over $\mathrm{PdAg}, \mathrm{PdAg}-\mathrm{CeO}_{2}, \mathrm{PdAg} / \mathrm{MC}$ and $\mathrm{PdAg}-\mathrm{CeO}_{2} / \mathrm{MC}$ catalysts, respectively $\left.\left(\mathrm{n}_{\mathrm{FA}} / \mathrm{n}_{\mathrm{SF}}=1 / 6 ; \mathrm{n}_{(\mathrm{Pd}+\mathrm{Ag})}\right) \mathrm{n}_{\mathrm{FA}}=0.033\right) ;(\mathbf{c})$ Catalytic performance of the PdAg- $\mathrm{CeO}_{2} / \mathrm{MC}$ catalysts with different $\mathrm{Pd} / \mathrm{Ag}$ molar ratios for FA dehydrogenation at $30{ }^{\circ} \mathrm{C}$ in a FA-SFs solution $\left(\mathrm{n}_{\mathrm{FA}} / \mathrm{n}_{\mathrm{SF}}=1 / 6 ; \mathrm{n}_{(\mathrm{Pd}+\mathrm{Ag})}: \mathrm{n}_{\mathrm{FA}}=0.033\right) ;(\mathrm{d})$ Catalytic performance of the optimised $\mathrm{Pd}_{0.8} \mathrm{Ag}_{0.2}-\mathrm{CeO}_{2} / \mathrm{MC}$ catalyst for FA dehydrogenation at $30^{\circ} \mathrm{C}$ in FA-SF solutions with different FA/SF molar ratios. Reprinted with permission from [72]. 
Figure 4a depicts the gas evolution profiles of the studied systems, which, together with TOF values displayed in Figure $4 b$, points out the superiority of the multicomponent catalyst. $\mathrm{PdAg}-\mathrm{CeO}_{2} / \mathrm{MC}$ catalyst had a TOF of $2272.8 \mathrm{~h}^{-1}$, which was more than 8 times that of $\mathrm{PdAg}$ and much higher than the sum of the individual components (i.e. $\mathrm{PdAg}-\mathrm{CeO}_{2}$ and $\mathrm{PdAg} / \mathrm{MC}$ ), which demonstrated the synergistic effect between mesoporous carbon and $\mathrm{PdAg}$ via modification with $\mathrm{CeO}_{2}$. Additionally, the effect of the $\mathrm{Pd}$ to $\mathrm{Ag}$ ratio in the nanoparticles was investigated and, as observed in Figure $4 \mathrm{c}$, the optimum value was found to be $8 / 2$.

The beneficial role of $\mathrm{CeO}_{2}$ in the decomposition of FA over carbon-based catalysts had been previously observed by other authors while investigating the use of $\mathrm{Pd}-\mathrm{Au} / \mathrm{C}$ and $\mathrm{Pd}-\mathrm{Ag} / \mathrm{C}$ catalysts [92]. In that study, the composition of the nanoparticles was firstly optimised by assessing the activity of $\mathrm{Pd} / \mathrm{C}$, $\mathrm{Pd}-\mathrm{Ag} / \mathrm{C}, \mathrm{Pd}-\mathrm{Au} / \mathrm{C}$, and $\mathrm{Pd}-\mathrm{Cu} / \mathrm{C}$ catalysts at $92{ }^{\circ} \mathrm{C}$. The results of the gas evolution profiles indicated the superior performance of $\mathrm{Pd}-\mathrm{Ag} / \mathrm{C}$ and $\mathrm{Pd}-\mathrm{Au} / \mathrm{C}$, which was related to the weaker interaction of $\mathrm{Ag}$ and $\mathrm{Au}$ with $\mathrm{CO}$ molecules. In that case, even though an enhanced activity was observed upon addition of $\mathrm{CeO}_{2}$, the reason for such improvement was not deeply analysed.

A more complex system was designed by Kim et al. [75]. In that study, bimetallic PdAg catalysts loaded on $\mathrm{Fe}_{3} \mathrm{O}_{4} /$ nitrogen-doped reduced graphene oxide $\left(\mathrm{PdAg} / \mathrm{Fe}_{3} \mathrm{O}_{4} / \mathrm{N}-\mathrm{rGO}\right)$ were prepared. The motivation of the preparation of such multicomponent catalysts was to obtain a dual-functional catalyst for the generation of $\mathrm{H}_{2}$ from $\mathrm{FA}$ and the subsequent utilisation of the generated $\mathrm{H}_{2}$ for the selective defunctionalisation of lignin-derived chemicals. The incorporation of $\mathrm{N}$ heteroatoms was claimed to favour the anchoring of the nanoparticles and promote the dehydrogenation reaction, while $\mathrm{Fe}_{3} \mathrm{O}_{4}$ was incorporated to achieve easy separation of the catalysts. The final catalysts were deeply characterised by means of microscopic analysis, which confirmed the good dispersion of the metallic phases and the formation of PdAg alloys (See Figure 5). The resulting $\mathrm{Pd}_{50} \mathrm{Ag}_{50} / \mathrm{Fe}_{3} \mathrm{O}_{4} / \mathrm{N}-\mathrm{rGO}$ displayed a TOF of $497 \mathrm{~h}^{-1}$ (at $50^{\circ} \mathrm{C}$ ) and CO was not detected.

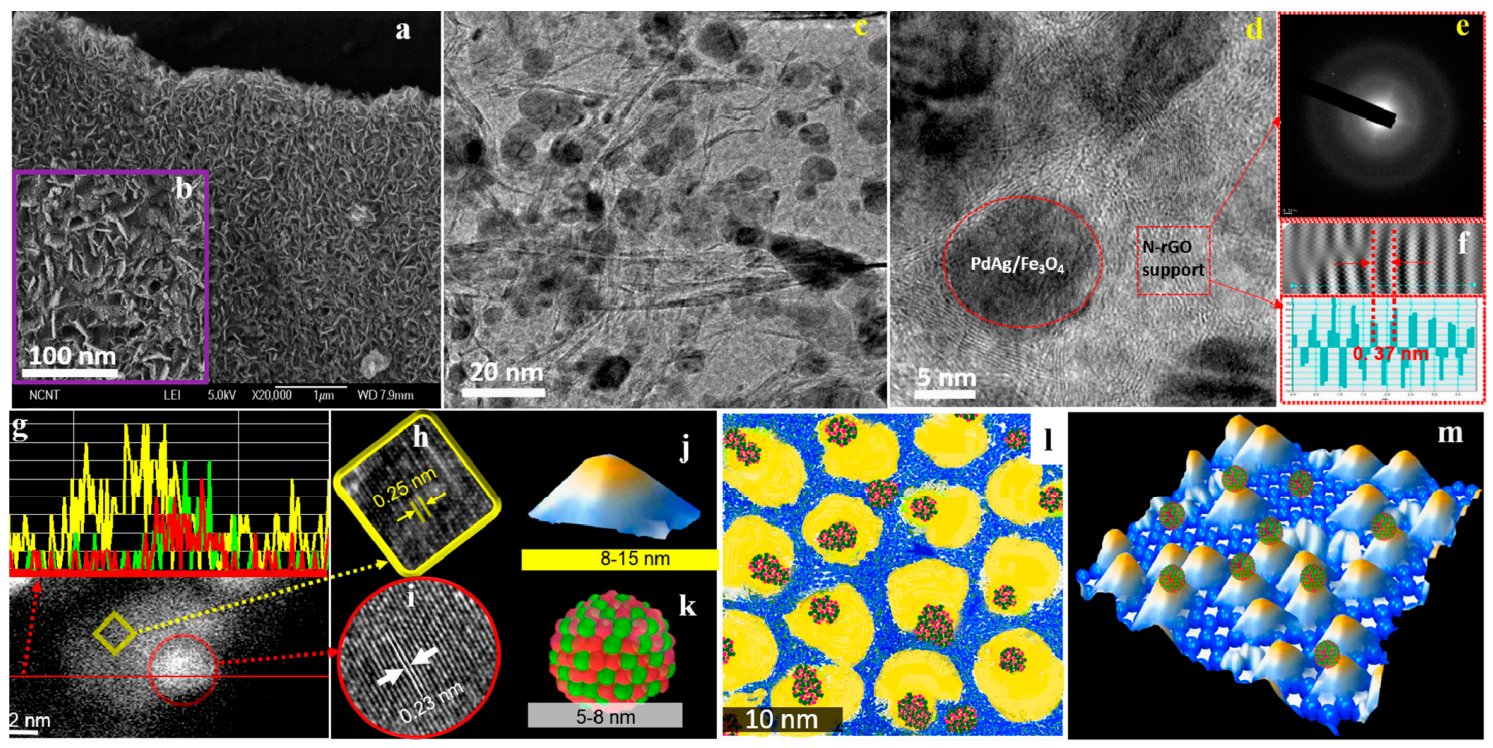

Figure 5. Microscopic analysis and proposed structure of $\mathrm{Pd}_{50} \mathrm{Ag}_{50} / \mathrm{Fe}_{3} \mathrm{O}_{4} / \mathrm{N}-\mathrm{rGO}$ catalyst: (a,b) SEM images; (c) low-resolution TEM analysis; (d) high-resolution TEM analysis; (e) selected area electron diffraction pattern of N-rGO layer; (f) d spacing from stacked N-rGO layers; (g) dark field HAADF images with elemental line profile (yellow line, Fe; green line, Pd; red line, Ag); (h,i) CS-corrected TEM images of magnetite and PdAg nanoalloy; (j,k) proposed models for $\mathrm{Fe}_{3} \mathrm{O}_{4}$ and $\mathrm{PdAg}$ nanoalloy; (1) 2D scratch art model (yellow, magnetite; blue background, N-rGO; and green/red cluster, PdAg alloy); (m) proposed 3D structural model. Reprinted with permission from [75]. 


\subsection{PdAg Catalysts Supported on Non-carbon Materials}

Besides the catalyst supports based on carbon materials, some other interesting materials have been employed as support of PdAg nanoparticles to prepare catalysts for the dehydrogenation of FA.

Motivated by the excellent performance achieved by those N-containing carbon-based catalysts, Lei et al. investigated the suitability of graphitic carbon nitride $\left(g-\mathrm{C}_{3} \mathrm{~N}_{4}\right)$ as support for the preparation of efficient PdAg-based catalysts [74]. Bimetallic AgPd nanoparticles were supported on $g-\mathrm{C}_{3} \mathrm{~N}_{4}$, previously prepared from melamine, by impregnation of metal precursors in different proportions and subsequent reduction in liquid phase with $\mathrm{NaBH}_{4}$, so that catalysts with various compositions of the nanoparticles $\left(\mathrm{Ag}_{4} \mathrm{Pd}_{96} / g-\mathrm{C}_{3} \mathrm{~N}_{4}, \mathrm{Ag}_{9} \mathrm{Pd}_{91} / g-\mathrm{C}_{3} \mathrm{~N}_{4}, \mathrm{Ag}_{16} \mathrm{Pd}_{84} / g-\mathrm{C}_{3} \mathrm{~N}_{4}, \mathrm{Ag}_{21} \mathrm{Pd}_{79} / g-\mathrm{C}_{3} \mathrm{~N}_{4}, \mathrm{Ag} / g-\mathrm{C}_{3} \mathrm{~N}_{4}\right.$, and $\mathrm{Pd} / g-\mathrm{C}_{3} \mathrm{~N}_{4}$ ) were obtained. The characterisation of the samples confirmed the presence of small and homogeneously distributed alloy nanoparticles. Among analysed samples, $\mathrm{Ag}_{9} \mathrm{Pd}_{91} / g-\mathrm{C}_{3} \mathrm{~N}_{4}$ exhibited the most promising performance with a TOF value as high as $480 \mathrm{~h}^{-1}$ at $50{ }^{\circ} \mathrm{C}$ and $100 \%$ of selectivity towards the production of $\mathrm{H}_{2}$.

Jia et al. also reported on the use of $g-\mathrm{C}_{3} \mathrm{~N}_{4}$-based catalysts [82]. In that case, $g-\mathrm{C}_{3} \mathrm{~N}_{4}$, synthesised from urea, was impregnated with $\mathrm{Ag}$ and $\mathrm{Pd}$ precursors to obtain catalysts with the following compositions: $\mathrm{Ag}_{1} \mathrm{Pd}_{2} / \mathrm{CN}, \mathrm{Ag}_{1} \mathrm{Pd}_{4} / \mathrm{CN}, \mathrm{Ag}_{1} \mathrm{Pd}_{1} / \mathrm{CN}, \mathrm{Ag}_{2} \mathrm{Pd}_{1} / \mathrm{CN}, \mathrm{Ag} / \mathrm{CN}$, and $\mathrm{Pd} / \mathrm{CN}$. The characterisation of the catalysts indicated that, in that case, electron-deficient Pd species were present. Such species were attributed to the formation of covalent $\mathrm{Pd}-\mathrm{N}_{\text {pyridinic }}$ bonds. The results of the catalytic tests revealed that $\mathrm{Ag}_{1} \mathrm{Pd}_{2} / \mathrm{CN}$ was the most active sample and had a TOF value of $621 \mathrm{~h}^{-1}$ at $75^{\circ} \mathrm{C}$ in absence of additives.

Wan et al. also addressed the use of $g-\mathrm{C}_{3} \mathrm{~N}_{4}$ as a useful approach to afford highly efficient catalysts for the present application [77]. In that case, the preparation of the catalysts was via immobilisation of $g-\mathrm{C}_{3} \mathrm{~N}_{4}$ within the channel of SBA-15 and subsequent deposition of AgPd nanoparticles with various $\mathrm{Ag}$ to $\mathrm{Pd}$ ratios $(\mathrm{Ag} / \mathrm{Pd}$ ratios of 1:9, 2:8, 3:7, 1:0, and 0:1) by a co-reduction method. Furthermore, $g-\mathrm{C}_{3} \mathrm{~N}_{4}$ content was also optimised. The results of the catalytic tests revealed that sample $\mathrm{Ag}_{10} \mathrm{Pd}_{90} / 0.2 \mathrm{CND} / \mathrm{SBA}-15$ displayed superior activity with a TOF value of $893 \mathrm{~h}^{-1}$ at $50{ }^{\circ} \mathrm{C}$.

Despite their poor stability in water, the utilisation of MOF-based catalysts was also investigated for the decomposition of FA by synthesising immobilised or embedded bimetallic metal nanoparticles. Cheng et al. reported for the first time the use of MOF as support of catalysts for this application [84]. In that study, MIL-101 was selected due to its high specific surface area, high thermal stability, and high chemical stability in water. MIL-101 was loaded with metal nanoparticles of various compositions ( $\mathrm{Ag}_{20} \mathrm{Pd}_{80} @$ MIL-101, $\mathrm{Ag}_{35} \mathrm{Pd}_{65} @ \mathrm{MIL}-101, \mathrm{Ag}_{48} \mathrm{Pd}_{52} @ \mathrm{MIL}-101, \mathrm{Ag}_{63} \mathrm{Pd}_{37} @ \mathrm{MIL}-101$, $\mathrm{Ag}_{78} \mathrm{Pd}_{22} @ \mathrm{MIL}-101, \mathrm{Ag} @ \mathrm{MIL}-101$, and Pd@MIL-101) by using $\mathrm{H}_{2} \mathrm{PdCl}_{4}$ and $\mathrm{AgNO}_{3}$ as metal precursors, after which the crystallinity of the support was preserved. The results extracted from TEM and $\mathrm{N}_{2}$ adsorption measurements revealed that the metal nanoparticles were immobilised into the cavities of the support. As expected, the activity of the catalysts was dependent on the composition of the nanoparticle, being optimum for $\mathrm{Ag}_{20} \mathrm{Pd}_{80} @ \mathrm{MIL}-101$ catalyst, which had a TOF value of $848 \mathrm{~h}^{-1}$ at $80^{\circ} \mathrm{C}$. In addition, the synergy between $\mathrm{AgPd}$ nanoparticles and the support was confirmed by comparison with reference catalysts.

The same research group also reported on the synergistic catalytic properties of AgPd nanoparticles encapsulated in the cages of ZIF-8 (AgPd@ZIF-8) by checking the activity of catalysts with different Ag/Pd ratio $\left(\mathrm{Ag}_{18} \mathrm{Pd}_{82} @ \mathrm{ZIF}-8, \mathrm{Ag}_{25} \mathrm{Pd}_{75} @ \mathrm{ZIF}-8, \mathrm{Ag}_{48} \mathrm{Pd}_{52} @ \mathrm{ZIF}-8, \mathrm{Ag}_{58} \mathrm{Pd}_{42} @ \mathrm{ZIF}-8\right.$, $\mathrm{Ag}_{76} \mathrm{Pd}_{24} @ Z \mathrm{ZIF}-8$, Ag@ZIF-8, and Pd@ZIF-8) that were synthesised by solution infiltration of ZIF-8 with the metal precursors and subsequent treatment with $\mathrm{NaBH}_{4}$ [83]. To ascertain the role of the support, $\mathrm{Ag}_{18} \mathrm{Pd}_{82}$ supported on carbon, $\mathrm{SiO}_{2}$, and $\mathrm{Al}_{2} \mathrm{O}_{3}$ were also prepared. In that case, sample $\mathrm{Ag}_{18} \mathrm{Pd}_{82} @ \mathrm{ZIF}-8$ had a considerable enhanced catalytic performance as compared to the monometallic $\mathrm{Pd}$ analogue, while higher content of $\mathrm{Ag}$ in the nanoparticles resulted in poorer performances. Moreover, the recyclability tests revealed that $\mathrm{Ag}_{18} \mathrm{Pd} \mathrm{d}_{82} @ \mathrm{ZIF}-8$ was still active after five catalytic runs and that the integrity of the framework of ZIF-8 was preserved. It was postulated in that 
study that the results displayed by $\mathrm{Ag}_{18} \mathrm{Pd}_{82} @ \mathrm{ZIF}-8$ were a consequence of the strong molecular-scale synergy of AgPd alloy with small size $(1.6 \pm 0.2 \mathrm{~nm})$.

Zhu et. al fabricated a core-shell AgPd@MOF catalyst based on MIL-100(Fe) and synthesised by a one-pot strategy [63]. The approach followed afforded the preparation of materials with uniform shape and controllable size, in which a uniform MIL-100(Fe) shell is coating the AgPd core. The synthetic method consisted in the formation of MIL-100(Fe) on the surface of the PVP-modified AgPd nanoparticles. The sizes of core and shell could be easily controlled by adjusting the concentration of the precursors used in the synthesis. In the case of AgPd nanoparticles, their sizes ranged from 14 to $86 \mathrm{~nm}$, while the shell thickness varied from 7 to $118 \mathrm{~nm}$. It was observed that the thickness of MIL-100(Fe) played an important role in the final catalytic performance. Thus, catalysts with the thinnest shell displayed the highest activity because of the fast mass transfer of FA molecules to the embedded metallic nanoparticles. Furthermore, the importance of the arrangement of AgPd nanoparticles and MIL-100(Fe) in a core-shell structure was also demonstrated. It was claimed that MIL-100(Fe) shell adsorbed FA molecules close to the active metal nanoparticles, favouring, therefore, the efficient contact between FA molecules and active sites that ultimately improved the catalytic performance.

A step further was taken by Gao et al., who explored the catalytic response of AgPd alloy nanoparticles encapsulated within an amine-functionalised UiO-66 (AgPd@ $\left.\mathrm{NH}_{2}-\mathrm{UiO}-66\right)$ [85]. In that case, the nitrogen functionalisation served as anchoring points for $\mathrm{Ag}$ and Pd precursor, which were immobilised within the pores via electrostatic interaction with $\mathrm{N}$-groups (See Figure 7). Catalysts with a molar ratio Ag:Pd of 1:4, 1:2, 1:1, 2:1, 4:1, 1:0 and 0:1, and high metal content (ranging from 3.80 to $13.10 \mathrm{wt}$ \%, and from 3.40 to $12.59 \mathrm{wt}$. \%, for $\mathrm{Ag}$ and $\mathrm{Pd}$, respectively) were synthesised by following the same experimental approach. Among investigated, $\mathrm{Ag}_{1} \mathrm{Pd}_{4} @ \mathrm{NH}_{2}-\mathrm{UiO}-66$ was the best-performing catalyst for the dehydrogenation of FA, with an initial TOF of $893 \mathrm{~h}^{-1}$ at $80^{\circ} \mathrm{C}$ and without any additive. It was assumed in that study that the promising catalytic performance shown by the studied system was due to the good dispersion of small AgPd nanoparticles and the basic properties of amino groups present in the catalyst.

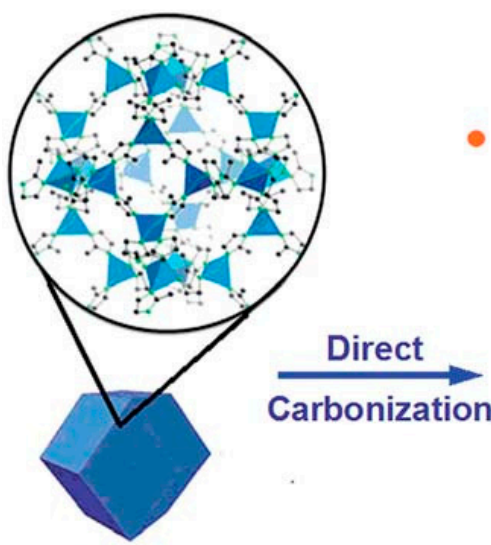

ZIF-8

\section{AgPd nanoparticle}

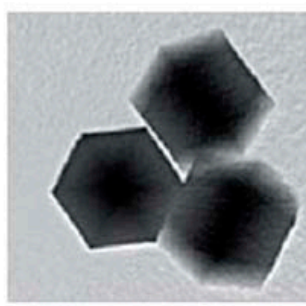

NPC

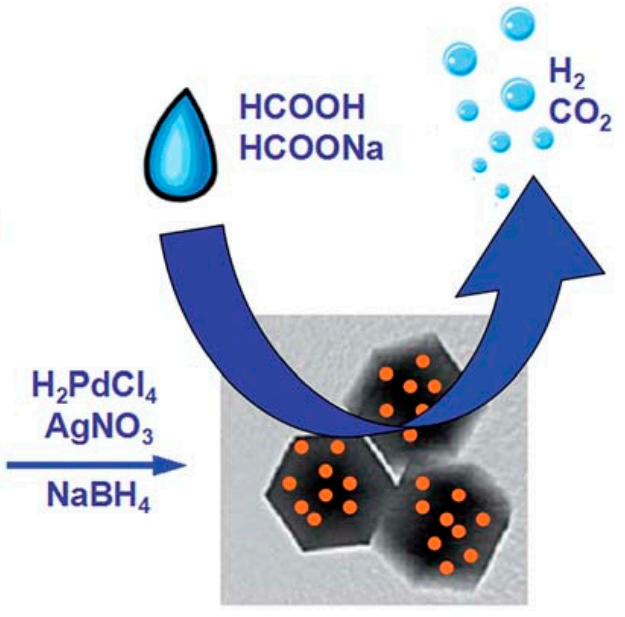

AgPd@NPC

( $\mathrm{Zn} \& \mathrm{~N}$ inside)

Figure 6. Schematic illustration for the preparation of AgPd@NPC. Reprinted with permission from [86]. 




Figure 7. Schematic representation of the synthesis process of the AgPd@NH $2-\mathrm{UiO}-66$. Reprinted with permission from [85].

In an attempt to apply different AgPd-based catalytic structures for the reaction under study, Tsuji et al. investigated the catalytic activity of AgPd-core Pd-shell nanoparticles supported on $\mathrm{TiO}_{2}$ prepared by a multistep method assisted by MW irradiation at different irradiation times (30 min, 1 h, or 2 h, for AgPd@Pd/TiO 2 (30 min), AgPd@Pd/TiO 2 (1 h), and $\mathrm{AgPd} @ \mathrm{Pd} / \mathrm{TiO}_{2}(2 \mathrm{~h})$ catalysts, respectively) so as to have different extent of alloying of the AgPd core [93]. The characterisation of the samples revealed that all catalysts had very similar nanoparticle size, composition and morphology regardless of the heating time. XPS analysis confirmed the presence of Ag-Pd alloy in the interface of Ag-rich core and Pd-shell. Aside from that, it was also suggested that there was an electron transfer from the support to $\mathrm{Ag}$ and $\mathrm{Pd}$. The dependence of the ability for the dehydrogenation of FA and the extent of alloying of the $\mathrm{AgPd}$ core was investigated with samples of various compositions $\mathrm{Ag}_{100-\mathrm{x}} \mathrm{Pd}_{\mathrm{x}}$ $\left(\mathrm{x}=7,10\right.$, and 15) $@ \mathrm{Pd} / \mathrm{TiO}_{2}$ and a similar average nanoparticles size of $4.6 \mathrm{~nm}$. It was observed that the best catalytic activity was displayed by $\mathrm{Ag}_{93} \mathrm{Pd}_{7} @ \mathrm{Pd} / \mathrm{TiO}_{2}$.

Akbayrak recently reported on the utilisation of tungsten (VI) oxide, $\mathrm{WO}_{3}$, which was selected due to its multiple oxidation states (that favour the electron transfer between support and nanoparticles) and strong metal-support interaction (SMSI) [76]. Catalysts with various compositions of the nanoparticles $\left(\mathrm{Ag}_{0.25} \mathrm{Pd} / \mathrm{WO}_{3}, \mathrm{Ag}_{0.5} \mathrm{Pd} / \mathrm{WO}_{3}, \mathrm{Ag}_{0.75} \mathrm{Pd} / \mathrm{WO}_{3}, \mathrm{Ag}_{1.0} \mathrm{Pd} / \mathrm{WO}_{3}, \mathrm{Ag}_{1.5} \mathrm{Pd} / \mathrm{WO}_{3}, \mathrm{Ag}_{0.25} / \mathrm{WO}_{3}\right)$ were prepared via a co-impregnation method. Among investigated, $\mathrm{Ag}_{0.25} \mathrm{Pd} / \mathrm{WO}_{3}$ was the optimum catalyst but, despite the good activity shown in the first reaction run (TOF value of $683 \mathrm{~h}^{-1}$ at $50{ }^{\circ} \mathrm{C}$ ), the second catalytic run evidenced its lack reusability due to aggregation of AgPd nanoparticles.

An et al. investigated the catalytic behaviour of amine-functionalized SBA-15 (SBA-15-Amine)-supported bimetallic AgPd nanoparticles [78]. According to the experimental methodology used in that study, 3-aminopropyltriethoxysilane (APTES) was used as amine source and the resulting SBA-15-Amine was loaded with $\mathrm{Ag}$ and Pd precursors in different proportions to obtain Pd/SBA-15-Amine, $\mathrm{Ag}_{1} \mathrm{Pd}_{9} / \mathrm{SBA}-15-\mathrm{Amine}, \mathrm{Ag}_{3} \mathrm{Pd}_{7} / \mathrm{SBA}-15-\mathrm{Amine}, \mathrm{Ag}_{5} \mathrm{Pd}_{5} / \mathrm{SBA}-15-\mathrm{Amine}$, $\mathrm{Ag}_{7} \mathrm{Pd}_{3} / \mathrm{SBA}-15-\mathrm{Amine}$, and $\mathrm{Ag} / \mathrm{SBA}-15-\mathrm{Amine}$ catalysts. It was observed that samples with moderate contents of $\mathrm{Ag}$ (i.e. $\mathrm{Ag}_{1} \mathrm{Pd}_{9} / \mathrm{SBA}-15-\mathrm{Amine}, \mathrm{Ag}_{3} \mathrm{Pd}_{7} / \mathrm{SBA}-15-\mathrm{Amine}$ ) showed enhanced performance as compared to $\mathrm{Pd}$ monometallic analogue, while higher Ag loading led to worsened activities. In particular, $\mathrm{Ag}_{1} \mathrm{Pd}_{9} / \mathrm{SBA}-15-\mathrm{Amine}$ was shown to have the highest TOF among the investigated $\left(964 \mathrm{~h}^{-1}\right.$ at $\left.50^{\circ} \mathrm{C}\right)$, which was attributed to a molecular-scale synergistic effect of the AgPd alloy.

Zahmakiran et al. reported on a catalytic architecture based on bimetallic PdAg alloy and $\mathrm{MnO}_{\mathrm{x}}$ nanoparticles supported on amine-grafted silica ( $\left.\mathrm{PdAg}-\mathrm{MnOx} / \mathrm{N}-\mathrm{SiO}_{2}\right)$ prepared from $\mathrm{Pd}\left(\mathrm{NO}_{3}\right) \cdot 2 \mathrm{H}_{2} \mathrm{O}$, $\mathrm{AgNO}_{3}$, and $\mathrm{Mn}\left(\mathrm{NO}_{3}\right)_{2} \cdot 4 \mathrm{H}_{2} \mathrm{O}$ as metal precursors, and 3-triethoxysilylpropylamine as the nitrogen source [62]. That investigation was based on a previous study of the same research group, in which the positive effect of $\mathrm{MnO}_{\mathrm{x}}$ as $\mathrm{CO}$ "trap" was observed [94]. Lately, they reported more complex catalysts based on bimetallic nanoparticles by using the same concept as that used for the monometallic system. Among the investigated compositions, catalysts with a composition of $\mathrm{Pd}_{0.44} \mathrm{Ag}_{0.19} \mathrm{Mn}_{0.37}$ (i.e., 
$1.27,0.57$, and 0.54 wt. \% of Pd, $\mathrm{Ag}$, and Mn, respectively) displayed the best catalytic performance. Furthermore, the comparison with the monometallic and binary counterpart catalysts confirmed the pivotal role of $\mathrm{Ag}$ in avoiding deactivation of the catalysts due to the generation of poison reaction by-products. In addition, control samples were also prepared by a physical mixture of the individual components (i.e. $\mathrm{Pd} / \mathrm{N}-\mathrm{SiO}_{2}, \mathrm{Ag} / \mathrm{N}-\mathrm{SiO}_{2}, \mathrm{Mn} / \mathrm{N}-\mathrm{SiO}_{2}$ ), whose inferior catalytic activity confirmed that the synergistic effect observed for $\mathrm{Pd}_{0.44} \mathrm{Ag}_{0.19}-\mathrm{Mn}_{0.37} / \mathrm{N}-\mathrm{SiO}_{2}$ is linked to the proximity of the components. A remarkable aspect of that catalytic system, is that it displayed total conversion of FA and high selectivity at room temperature and in absence of additives, and it retained $86 \%$ of the initial activity after five consecutive reaction runs. The effect of grafted amine groups was also investigated, observing that, under the experimental conditions used, the optimum amine loading was $0.98 \mathrm{mmol}$ $\mathrm{NH}_{2} / \mathrm{g}$. It was claimed that the positive effect of $-\mathrm{NH}_{2}$ groups was related to the $\mathrm{FA}$ adsorption/storage process and the formation of $\mathrm{PdAg}$ and $\mathrm{MnO}_{x}$ nanoparticles on the surface of the support. In addition, the beneficial effect of $\mathrm{MnO}_{\mathrm{x}}$ was related to its ability to serve as a "pinning/anchoring site" for CO molecules, avoiding, therefore, the poisoning of PdAg catalytic active sites. Later, Wang et al. also incorporated $\mathrm{MnO}_{\mathrm{x}}$ to the synthesis of the catalytic system used for the dehydrogenation of FA [80]. In that case, $\mathrm{AgPd}-\mathrm{MnO}_{\mathrm{x}}$ supported on carbon nanospheres derived from biomass (i.e. sucrose) were investigated. It was observed that the catalysts displayed a promising activity and selectivity, with a TOF value of $3558 \mathrm{~h}^{-1}$ at $50{ }^{\circ} \mathrm{C}$ and with the addition of potassium formate (HCOOK) as an additive.

\subsection{Photocatalytic Decomposition of Formic Acid}

Recently, the decomposition of FA has also been tackled from the photocatalytic viewpoint. This approach is of great interest in the current energy scenario since it could join two aspects of the realisation of a sustainable energy future: the utilisation of sunlight, as a green and abundant energy source, and the production of hydrogen from a molecule that is potentially suitable for the carbon-neutral energy storage system. Despite its interest, few studies have been reported so far on the utilisation of photocatalytic systems based on PdAg bimetallic nanoparticles for the dehydrogenation of FA. Most of those studies address the use of the so-called Mott-Schottky heterojunctions, formed by a semiconductor support and metal nanoparticles, but some other strategies, such as the use of capping agents [95], can be also found in the literature.

Starting with $\mathrm{TiO}_{2}$, as the photocatalytic material par excellence, Ago et al. investigated the catalysis of core-shell AgPd nanoparticles supported on $\mathrm{TiO}_{2}\left(\mathrm{AgPd} @ \mathrm{Pd} / \mathrm{TiO}_{2}\right)$ [96]. As in the previous study reported by the same group, in which the production of $\mathrm{H}_{2}$ was done by thermal decomposition of FA [93], the composition of metal nanoparticles was modified by dealloying the core of the nanoparticles for the preparation of $\mathrm{Ag}_{100-\mathrm{x}} \mathrm{Pd}_{\mathrm{x}} @ \mathrm{Pd} / \mathrm{TiO}_{2}$ catalysts, with $\mathrm{x}=7,10,15$. In this case, the most promising composition of the nanoparticles was $\mathrm{Ag}_{93} \mathrm{Pd}_{7} @ \mathrm{Pd} / \mathrm{TiO}_{2}$. Moreover, the effect of the support was also evaluated by using anatase (A) and the commercial $\mathrm{TiO}_{2}$ P25 (P). The resulting materials had a Pd shell with a thickness of $0.8 \mathrm{~nm}$ for both $\mathrm{A}$ and $\mathrm{P}$, and the morphology, size, and composition of the nanoparticles were similar regardless of the $\mathrm{TiO}_{2}$ used. In order to monitor the photocatalytic response of the samples, gas evolution profiles were registered while irradiating the samples with a Xe lamp and heating at $27,40,60,70$, and $90^{\circ} \mathrm{C}$. For all the temperatures, the performance was superior for the illuminated samples, but some differences were observed for low and high temperatures. The analysis of the resulting data revealed that the initial reaction rate was enhanced by a factor of 1.5-1.6 upon irradiation of $\mathrm{AgPd} @ \mathrm{Pd} / \mathrm{TiO}_{2}(\mathrm{~A})$ and $\mathrm{AgPd} @ \mathrm{Pd} / \mathrm{TiO}_{2}(\mathrm{P})$ at $27^{\circ} \mathrm{C}$, but such enhancement factor was 1.1-1.2 at $90^{\circ} \mathrm{C}$. The differences were claimed to depend on the migration of photogenerated electrons from $\mathrm{TiO}_{2}$ to $\mathrm{Pd}$. At low reaction temperatures, the electron transfer from the conduction band of $\mathrm{TiO}_{2}$ to Pd shell takes place due to the difference in work function values $(5.1,4.7$, and $4.0 \mathrm{eV}$ for Pd, $\mathrm{Ag}$, and $\mathrm{TiO}_{2}$, respectively) and such electron-rich species are responsible for the enhancement of the catalytic performance (See Figure 8). Meanwhile, at higher temperatures, the electrons have higher migration rate, but the recombination of electron-hole pairs is favoured, leading to the reduction of 
the number of electrons on the Pd surface. Furthermore, the evaluation of the photocatalytic activity of $\mathrm{AgPd} @ \mathrm{Pd} / \mathrm{TiO}_{2}(\mathrm{~A})$ and $\mathrm{AgPd} @ \mathrm{Pd} / \mathrm{TiO}_{2}(\mathrm{P})$ revealed the better performance of the anatase-based catalyst, which was attributed to the higher specific surface area and strong interaction of anatase phase with AgPd@Pd particles as well as to the slower electron-hole recombination compared to rutile phase of P25.

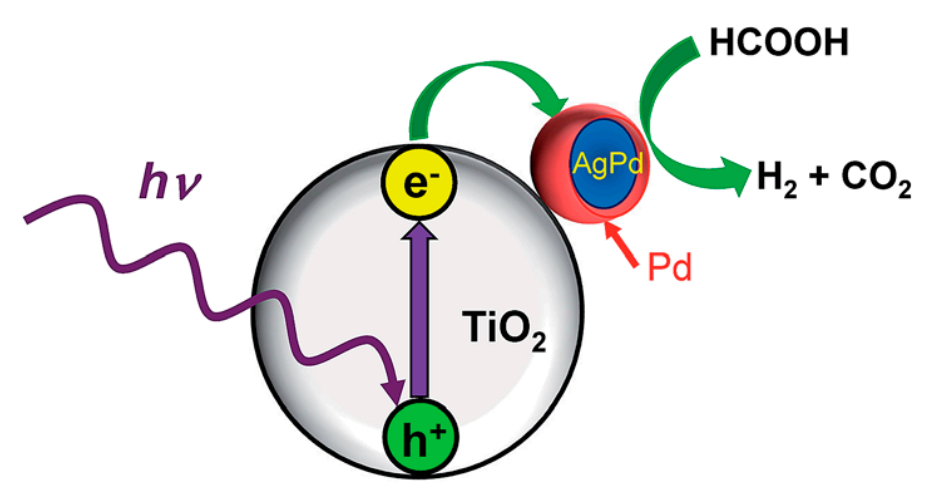

Figure 8. Enhancement mechanism of catalytic activity of $\mathrm{AgPd} @ \mathrm{Pd} / \mathrm{TiO}_{2}$ under $\mathrm{UV}$ and Vis photoirradiation. Reprinted with permission from [96].

Visible light-assisted photodecomposition of FA has also been investigated. Stucky et al. reported their study on $\mathrm{AgPd}$ bimetallic nanocrystals supported on $g-\mathrm{C}_{3} \mathrm{~N}_{4}$ [97]. That support was not only selected considering its ability for anchoring metal nanoparticles and assisting the dehydrogenation reaction, but also because of the favourable electron transfer to the metal active phase. In that case, mesoporous hollow $\mathrm{C}_{3} \mathrm{~N}_{4}$ spheres were used due to their better photoelectric features and higher surface area compared with conventional $\mathrm{C}_{3} \mathrm{~N}_{4}$. Nanoparticles with a Ag:Pd ratio of 1:1 and an average size of $7.5 \pm 1.0 \mathrm{~nm}$ were synthesised, and the photocatalytic ability of the resulting materials towards the $\mathrm{H}_{2}$ production from FA was assessed. The comparison of that catalyst with reference samples, based on activated carbon and silica, pointed out the importance of the support in achieving well-dispersed AgPd nanocrystals. XPS analysis also confirmed the electron donation from surface unsaturated nitrogen atoms of the support to Pd. The formation of such surface electron-rich Pd species can be further promoted upon illumination via photoelectron transfer from the support, which ultimately suppresses the electron-hole pair recombination. As a consequence of such features, the developed catalyst showed excellent ability towards the dehydrogenation of FA under visible light irradiation. A set of photocatalysts with similar nanoparticle size and same metal loading was prepared to evaluate the effect of the composition of the nanoparticles ( $\mathrm{Ag} 3 \mathrm{Pd}, \mathrm{AgPd}, \mathrm{AgPd} 3$, and Pd). It was observed that the catalyst with a composition Ag:Pd of 1:1 displayed the highest TOF among analysed samples (91 and $254 \mathrm{~h}^{-1}$, under dark and visible light irradiation at $30{ }^{\circ} \mathrm{C}$, respectively), which was much higher than those values calculated for the monometallic analogue catalyst (48 and $137 \mathrm{~h}^{-1}$, respectively).

$\mathrm{Yu}$ et. al. recently addressed the fabrication of Mott-Schottky heterojunctions constituted by $\mathrm{PdAg}$ nanowires (NWs) on $g-\mathrm{C}_{3} \mathrm{~N}_{4}$ [98]. Bimetallic NWs with various $\mathrm{Pd} / \mathrm{Ag}$ ratio were formed in-situ on the support to fabricate photocatalysts with various compositions $\left(\mathrm{Pd}_{7} \mathrm{Ag}_{3} \mathrm{NWs} @ g-\mathrm{C}_{3} \mathrm{~N}_{4}, \mathrm{Pd}_{5} \mathrm{Ag}_{5}\right.$


samples revealed that $\mathrm{Pd}$ species were electron-enriched due to the electron transfer from both $\mathrm{Ag}$ and $g-\mathrm{C}_{3} \mathrm{~N}_{4}$. It was reported that $\mathrm{O}-\mathrm{H}$ bond dissociation was favoured by the presence of electron-rich $\mathrm{Pd}$ species, as well as by the support, which acts as proton scavenger. As expected, the catalytic activity was strongly dependent on the composition of the nanoparticles, and initial TOF values of 346, 420, 242, and $105 \mathrm{~h}^{-1}$, were achieved for $\mathrm{Pd}_{7} \mathrm{Ag}_{3} \mathrm{NWs} @ g-\mathrm{C}_{3} \mathrm{~N}_{4}, \mathrm{Pd}_{5} \mathrm{Ag} 5 \mathrm{NWs} @ g-\mathrm{C}_{3} \mathrm{~N}_{4}, \mathrm{Pd}_{3} \mathrm{Ag} 7 \mathrm{NWs} @ g-\mathrm{C}_{3} \mathrm{~N}_{4}$ and Pd NWs@g- $\mathrm{C}_{3} \mathrm{~N}_{4}$, respectively, while monitoring the reaction under visible light irradiation and at $25^{\circ} \mathrm{C}$. Besides, $\mathrm{Pd}_{5} \mathrm{Ag}_{5} \mathrm{NWs} @ g-\mathrm{C}_{3} \mathrm{~N}_{4}$ was further used to study the effect of the concentration of the catalysts, the concentration of FA, reaction temperature, and visible light intensity, on the performance 
towards the $\mathrm{H}_{2}$ production. The stability of the photocatalysts was also investigated by carrying out four consecutive photocatalytic runs, after which the initial activity of $\mathrm{Pd}_{5} \mathrm{Ag}_{5} \mathrm{NWs} @ g-\mathrm{C}_{3} \mathrm{~N}_{4}$ was preserved.

\subsection{Theoretical Investigations}

The supremacy of PdAg-catalysts over other compositions of the active metal phase has widely been demonstrated from experimental investigations but also by theoretical studies. As for many other reactions [99-102], density functional theory (DFT) calculations have been used to study the decomposition of FA. Huang et al. reported a DFT study for the decomposition of FA over noble metals ( $\mathrm{Pt}, \mathrm{Au}, \mathrm{Pd}$, etc.) in both liquid and gas phase [103]. The energy profiles revealed that Pd-based surfaces favoured the decomposition of FA in the gas phase. However, that model could not be used to elucidate the decomposition of FA in aqueous phase. To do that, the solvation model of metal was used to get more realistic insights and the authors assumed that $\mathrm{CO}_{2}$ was dissolved, and it did not have any influence in surface reactions. Regarding $\mathrm{H}_{2}$ evolution, they considered that homolytic Tafel reaction played a pivotal role in the decomposition of FA, and it was concluded that the Pd surface displayed the lowest global energy barrier. Additionally, the authors pointed out that such a model could be used to study bimetallic alloys. A model cluster with two layers of Pd and two layers of $\mathrm{Ag}$ was built to explain the enhanced behaviour of PdAg bimetallic systems as compared to Pd monometallic catalysts.

An interesting study about transition metal catalysts in the decomposition of FA was reported by Studt et al. [104]. That study dealt with calculations of the reaction energetics in the decomposition of FA on transition-metal surfaces $(\mathrm{Ag}, \mathrm{Cu}, \mathrm{Pd}$, etc.) using DFT. Additionally, that model allowed to get insights into the kinetics of the decomposition of FA over the transition-metal catalysts. The authors considered three pathways to produce $\mathrm{CO}_{2}$ and $\mathrm{H}_{2}$, while only one route of dehydration was taken into consideration (Figure 9).

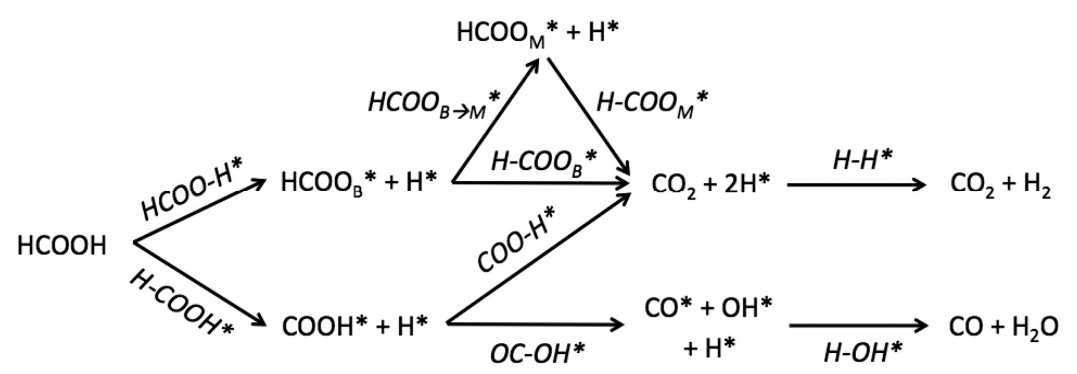

Figure 9. Reaction mechanism of FA decomposition. Reprinted with permission from [104].

All studied surfaces favoured the dehydrogenation rather than the dehydration pathway, and $\mathrm{Pd}$ surfaces displayed lower free-energy barriers than other transition metal surfaces. Other transition metal surfaces were explored by using the estimated adsorption energies of the species involved in the reaction over monometallic surfaces. From the TOFs values obtained in the decomposition of FA towards $\mathrm{H}_{2}$ and $\mathrm{CO}_{2}$, it was observed that monometallic noble metals did not display the best activity. It was found that Pd-based alloys with $\mathrm{Au}$ or $\mathrm{Ag}$ led to high selectivity to $\mathrm{H}_{2}$ and $\mathrm{CO}_{2}$ production. Moreover, the model could predict the low activity toward the $\mathrm{CO}$ formation, which is an extremely important factor for practical application in fuel cells. The selectivity towards either dehydrogenation or dehydration was studied by Ham et al [105]. The authors reported a theoretical study of PdAg-based catalysts for the decomposition of FA using the spin-polarized DFT to clarify which factors determine the selectivity of the reaction. The study was addressed for the evaluation of the impact of the Pd layer thickness over the enhancement of selectivity towards $\mathrm{H}_{2}$ formation. They realised that the reaction rate of the dehydrogenation pathway depended on the number of Pd layers covering the Ag substrate, and the highest activity was attained for the lower thickness of the Pd layer. Furthermore, both lattice parameters and electronic structure in Pd-Ag catalysts were also discussed. It was observed that 
a charge transfer from Ag substrate to Pd monolayer favoured the dehydrogenation of FA, while strain effects partially hindered the $\mathrm{H}_{2}$ production.

Cheng et al. recently published a comprehensive study towards the surface engineering structure of Pd-based alloy catalysts in which the relationship between the surface structure of the catalysts and their performance in the decomposition of FA was analysed by means of DFT and Sabatier analysis combined with experimental data [106]. In that case, not only PdAg alloys were analysed, but seven compositions of the nanoparticles ( $\mathrm{Pd}-\mathrm{M} ; \mathrm{M}=\mathrm{Ag}, \mathrm{Au}, \mathrm{Cu}, \mathrm{Ni}, \mathrm{Ir}, \mathrm{Pt}$, and $\mathrm{Rh}$ ) and five atomic arrangements (i.e. overlayer structure, core-shell structured $\mathrm{Pd} @ \mathrm{M}$, core-shell structured Pd@Pd-M, uniform alloy, and a subsurface structure) were studied (see Figure 10). As a result of that analysis, two surface structures (i.e. $\mathrm{Pd}_{2 \mathrm{~L}} @ \mathrm{Pd}_{1} \mathrm{Ag}_{1}$ and $\mathrm{Pd}_{2 \mathrm{~L}} @ \mathrm{Pd}_{1} \mathrm{Au}_{1}$ ) were identified as potential good candidates to boost the selective dehydrogenation of FA.

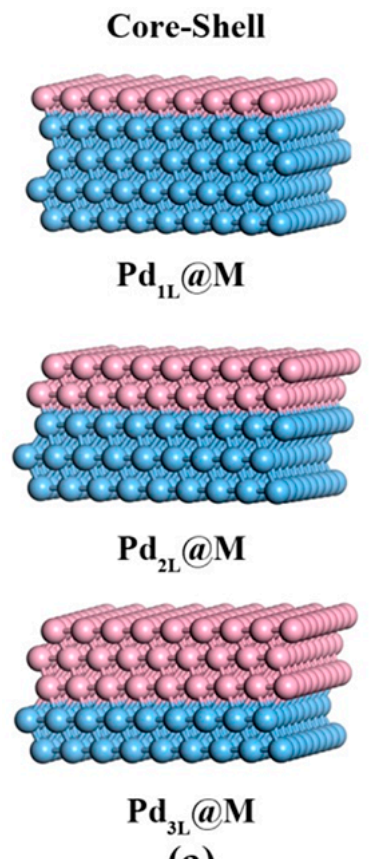

(a)

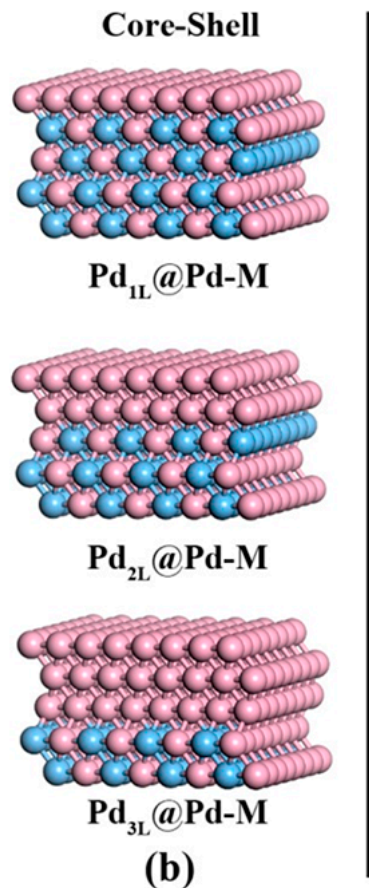

(b)

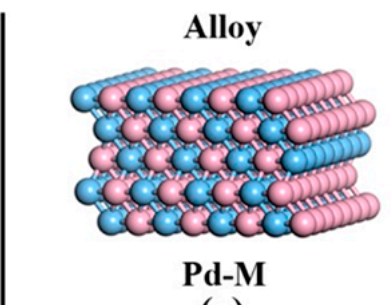

(c)
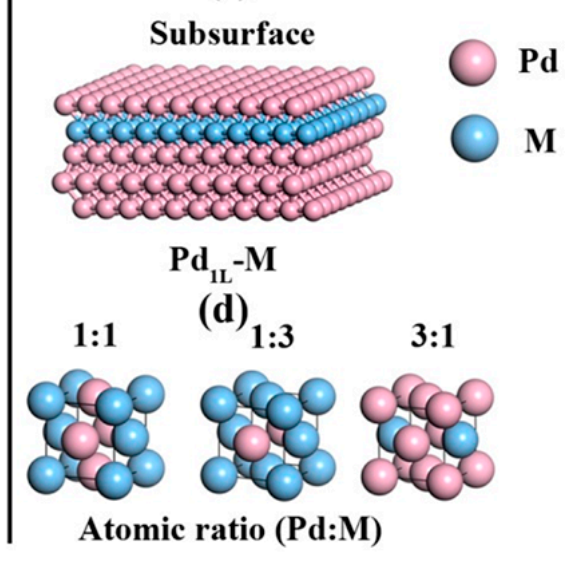

Figure 10. Models for the surface structures: (a) core-shell with Pd-M, (b) core-shell with a Pd alloy, (c) alloy, and (d) subsurface. Reprinted with permission from [106].

These studies evidence the importance of the theoretical outcomes for the optimisation of the composition and architecture of binary alloys based on Pd-Ag to obtain high-performance catalysts for the decomposition of FA.

\section{Conclusions}

The present review summarises some of the recent works on heterogeneous bimetallic PdAg catalytic systems for the production of $\mathrm{H}_{2}$ from formic acid. The importance of the target reaction is contextualised by highlighting the crucial role of $\mathrm{H}_{2}$ in the future energy scenario, as well as by pointing out the importance of $\mathrm{LOHC}$ to overcome the limitations displayed by conventional hydrogen technologies. The dehydrogenation of FA has widely been explored, while investigating diverse factors, such as the importance of the properties of the metal active phase and support, as well as the reaction conditions. In some other cases, the effect of the experimental conditions (i.e. concentration of FA and/or additives) has also been evaluated, but very little is known about the performance of the catalysts in high concentrated FA solutions. Theoretical investigations have also been conducted so as to ascertain the important characteristics to develop high-performance catalysts. Among those heterogeneous catalytic systems under investigation, the supremacy of Pd-based catalysts is undeniable. However, it is 
well-known at this point that the combination of $\mathrm{Pd}$ with a second metal provides enhanced catalytic performance due to the resulting electrical properties and resistance against $\mathrm{CO}$ poisoning effect. In particular, the use of PdAg-bimetallic systems offers outstanding results, which have motivated the search for multiple options for the optimisation of PdAg-bimetallic systems while getting insight into the role of the composition and structure of the nanoparticles, the properties of the catalytic support, the development of photocatalytic systems, and so forth. Concerning the properties of the metal active phase, the need for developing cost-effective catalysts has boosted the search for new metal nanoarchitectures with a larger fraction of surface Pd active sites. It has also been demonstrated that the incorporation of basic nitrogen functionalities into the support can greatly enhance the catalytic performance by two main effects: i) serving as anchoring points of metal active sites and avoiding the aggregation of the nanoparticles; ii) favouring the dissociation of the $\mathrm{O}-\mathrm{H}$ bond of FA molecules. Moreover, the presence of $\mathrm{N}$-containing groups has been related in some cases to the tunable reducibility of $\mathrm{Ag}$ and $\mathrm{Pd}$, hence contributing to the surface engineering of the bimetallic structures. It has also been observed that the use PdAg-based photocatalysts are a promising alternative to afford suitable activity and selectivity values at room or moderate temperatures. However, few reports on that approach have been reported so far.

Despite the efforts devoted so far towards the design and development of PdAg-based bimetallic catalysts for the production of $\mathrm{H}_{2}$ from $\mathrm{FA}$, there are still some major shortcomings that limit their practical application and that should be the focus of future investigations. One of them is the need for extra additives, generally in the form of formate (HCOONa or HCOOK), as well as high temperatures, that are detrimental to the practical application of $\mathrm{FA}$ as a $\mathrm{H}_{2}$ storage molecule. Developing catalytic systems able to produce $\mathrm{H}_{2}$ from additive-free reaction medium while displaying high activity and selectivity is highly desirable. Another weak point of most catalysts developed so far is their stability, since an important decay is normally observed after a few consecutive catalytic runs. The deactivation issue is frequently related with changes in the properties of the nanoparticles, in terms of size and/or electronic properties, as well as with leaching of the metal active phase, but some other aspects such as the adsorption of reaction intermediates and $\mathrm{CO}$ poisoning have been also observed in some studies. It has been shown in some cases that the deactivation of the catalysts is less marked for bimetallic PdAg-based catalysts than for the monometallic counterpart, but this aspect is still focus of improvement. It could be envisaged that an interesting alternative could be the use of advanced encapsulated metal catalysts, in which the active phase is protected from leaching and/or surface modification while securing the mass transfer to and from its surface. Great achievements have recently been reported while investigating on the catalytic performance of PdAg-based catalysts; however, there is still a lot of work to be done to reach the maturity level accomplished with monometallic Pd catalysts. It is expected that more research groups will be soon interested in the fascinating field of research related to the production of $\mathrm{H}_{2}$ from hydrogen carrier molecules, so that the worldwide scientific community can join their efforts towards the drawing of a hopeful energy prospect.

Author Contributions: M.N.-G. designed the structure of the review and wrote the manuscript, D.S.-T. contributed to the writing of the manuscript, and D.C.-A. reviewed the paper. All authors approved the manuscript for publication.

Funding: The authors would like to thank Generalitat Valenciana (PROMETEO/2018/076 project) for the financial support. Furthermore, M.N.-G. gratefully acknowledges Generalitat Valenciana and Plan GenT (CDEIGENT/2018/027) for the postdoctoral grant. D.S.-T. thanks MICINN for a "Juan de la Cierva" postdoctoral contract (IJCI-2016-27636).

Conflicts of Interest: The authors declare no conflict of interest.

\section{References}

1. United States Environmental Protection Agency. Available online: https://www.epa.gov/ghgemissions/ understanding-global-warming-potentials (accessed on 13 September 2019). 
2. Arrhenius, S. XXXI. On the influence of carbonic acid in the air upon the temperature of the ground. Lond. Edinb. Dublin Philos. Mag. J. Sci. 1896, 41, 237-276. [CrossRef]

3. Hook, M.; Tang, X. Depletion of fossil fuels and anthropogenic climate change-A review. Energy Policy 2013, 52, 797-809. [CrossRef]

4. Abas, N.; Kalair, A.; Khan, N. Review of fossil fuels and future energy technologies. Futures 2015, 69, 31-49. [CrossRef]

5. Alvarez, A.; Bansode, A.; Urakawa, A.; Bavykina, A.V.; Wezendonk, T.A.; Makkee, M.; Gascon, J.; Kapteijn, F. Challenges in the Greener Production of Formates/Formic Acid, Methanol, and DME by Heterogeneously Catalyzed CO2 Hydrogenation Processes. Chem. Rev. 2017, 117, 9804-9838. [CrossRef]

6. Artz, J.; Muller, T.E.; Thenert, K.; Kleinekorte, J.; Meys, R.; Sternberg, A.; Bardow, A.; Leitner, W. Sustainable Conversion of Carbon Dioxide: An Integrated Review of Catalysis and Life Cycle Assessment. Chem. Rev. 2018, 118, 434-504. [CrossRef] [PubMed]

7. Yang, Y.; Ajmal, S.; Zheng, X.; Zhang, L. Efficient nanomaterials for harvesting clean fuels from electrochemical and photoelectrochemical CO2 reduction. Sustain. Energy Fuels 2018, 2, 510-537. [CrossRef]

8. Abdalla, A.M.; Hossain, S.; Nisfindy, O.B.; Azad, A.T.; Dawood, M.; Azad, A.K. Hydrogen production, storage, transportation and key challenges with applications: A review. Energy Convers. Manag. 2018, 165, 602-627. [CrossRef]

9. Berenguer-Murcia, A.; Marco-Lozar, J.P.; Cazorla-Amoros, D. Hydrogen Storage in Porous Materials: Status, Milestones, and Challenges. Chem. Rec. 2018, 18, 900-912. [CrossRef]

10. Jang, M.; Jo, Y.S.; Lee, W.J.; Shin, B.S.; Sohn, H.; Jeong, H.; Jang, S.C.; Kwak, S.K.; Kang, J.W.; Yoon, C.W. A High-Capacity, Reversible Liquid Organic Hydrogen Carrier: $\mathrm{H}_{2}$ - Release Properties and an Application to a Fuel Cell. ACS Sustain. Chem. Eng. 2019, 7, 1185-1194. [CrossRef]

11. Niermann, M.; Drunert, S.; Kaltschmitt, M.; Bonhoff, K. Liquid organic hydrogen carriers (LOHCs)_Techno-economic analysis of LOHCs in a defined process chain. Energy Environ. Sci. 2019, 12, 290-307. [CrossRef]

12. Modisha, P.M.; Ouma, C.N.M.; Garidzirai, R.; Wasserscheid, P.; Bessarabov, D. The Prospect of Hydrogen Storage Using Liquid Organic Hydrogen Carriers. Energy Fuels 2019, 33, 2778-2796. [CrossRef]

13. Preuster, P.; Papp, C.; Wasserscheid, P. Liquid Organic Hydrogen Carriers (LOHCs): Toward a Hydrogen-free Hydrogen Economy. Acc. Chem. Res. 2017, 50, 74-85. [CrossRef] [PubMed]

14. Enthaler, S.; Von Langermann, J.; Schmidt, T. Carbon dioxide and formic acid-The couple for environmental-friendly hydrogen storage? Energy Environ. Sci. 2010, 3, 1207-1217. [CrossRef]

15. Masuda, S.; Mori, K.; Futamura, Y.; Yamashita, H. PdAg Nanoparticles Supported on Functionalized Mesoporous Carbon: Promotional Effect of Surface Amine Groups in Reversible Hydrogen Delivery/Storage Mediated by Formic Acid/CO2. ACS Catal. 2018, 8, 2277-2285. [CrossRef]

16. Salinas-Torres, D.; Navlani-Garcia, M.; Mori, K.; Kuwahara, Y.; Yamashita, H. Nitrogen-doped carbon materials as a promising platform toward the efficient catalysis for hydrogen generation. Appl. Catal. A Gen. 2019, 571, 25-41. [CrossRef]

17. Eppinger, J.; Huang, K.-W. Formic Acid as a Hydrogen Energy Carrier. ACS Energy Lett. 2017, 2, $188-195$. [CrossRef]

18. Coffey, R.S. The decomposition of formic acid catalysed by soluble metal complexes. Chem. Commun. 1967, 18, 923-924. [CrossRef]

19. Fellay, C.; Dyson, P.J.; Laurenczy, G. A viable hydrogen-storage system based on selective formic acid decomposition with a ruthenium catalyst. Angew. Chem. Int. Ed. 2008, 47, 3966-3968. [CrossRef]

20. Loges, B.; Boddien, A.; Junge, H.; Beller, M. Controlled generation of hydrogen from formic acid amine adducts at room temperature and application in H2/O2 fuel cells. Angew. Chem. Int. Ed. 2008, 47, 3962-3965. [CrossRef]

21. Iglesias, M.; Oro, L.A. Mechanistic Considerations on Homogeneously Catalyzed Formic Acid Dehydrogenation. Eur. J. Inorg. Chem. 2018, 2018, 2125-2138. [CrossRef]

22. Grasemann, M.; Laurenczy, G. Formic acid as a hydrogen source-Recent developments and future trends. Energy Environ. Sci. 2012, 5, 8171. [CrossRef]

23. Li, Z.; Xu, Q. Metal-Nanoparticle-Catalyzed Hydrogen Generation from Formic Acid. Acc. Chem. Res. 2017, 50, 1449-1458. [CrossRef] [PubMed]

24. Onishi, N.; Iguchi, M.; Yang, X.; Kanega, R.; Kawanami, H.; Xu, Q.; Himeda, Y. Development of Effective Catalysts for Hydrogen Storage Technology Using Formic Acid. Adv. Energy Mater. 2019, 9. [CrossRef] 
25. Sordakis, K.; Tang, C.; Vogt, L.K.; Junge, H.; Dyson, P.J.; Beller, M.; Laurenczy, G. Homogeneous Catalysis for Sustainable Hydrogen Storage in Formic Acid and Alcohols. Chem. Rev. 2018, 118, 372-433. [CrossRef] [PubMed]

26. Tedsree, K.; Li, T.; Jones, S.; Chan, C.W.A.; Yu, K.M.K.; Bagot, P.A.J.; Marquis, E.A.; Smith, G.D.W.; Tsang, S.C.E. Hydrogen production from formic acid decomposition at room temperature using a Ag-Pd core-shell nanocatalyst. Nat. Nanotechnol. 2011, 6, 302-307. [CrossRef] [PubMed]

27. Onishi, N.; Laurenczy, G.; Beller, M.; Himeda, Y. Recent progress for reversible homogeneous catalytic hydrogen storage in formic acid and in methanol. Coord. Chem. Rev. 2018, 373, 317-332. [CrossRef]

28. Mellmann, D.; Sponholz, P.; Junge, H.; Beller, M. Formic acid as a hydrogen storage material-development of homogeneous catalysts for selective hydrogen release. Chem. Soc. Rev. 2016, 45, 3954-3988. [CrossRef] [PubMed]

29. Hong, W.; Kitta, M.; Tsumori, N.; Himeda, Y.; Autrey, T.; Xu, Q. Immobilization of highly active bimetallic PdAu nanoparticles onto nanocarbons for dehydrogenation of formic acid. J. Mater. Chem. A 2019, 7, 18835-18839. [CrossRef]

30. Wang, Q.; Chen, L.; Liu, Z.; Tsumori, N.; Kitta, M.; Xu, Q. Phosphate-Mediated Immobilization of High-Performance AuPd Nanoparticles for Dehydrogenation of Formic Acid at Room Temperature. Adv. Funct. Mater. 2019, 29, 1903341. [CrossRef]

31. Wang, Q.; Tsumori, N.; Kitta, M.; Xu, Q. Fast Dehydrogenation of Formic Acid over Palladium Nanoparticles Immobilized in Nitrogen-Doped Hierarchically Porous Carbon. ACS Catal. 2018, 8, 12041-12045. [CrossRef]

32. Song, F.Z.; Zhu, Q.L.; Yang, X.; Zhan, W.W.; Pachfule, P.; Tsumori, N.; Xu, Q. Metal-Organic Framework Templated Porous Carbon-Metal Oxide/Reduced Graphene Oxide as Superior Support of Bimetallic Nanoparticles for Efficient Hydrogen Generation from Formic Acid. Adv. Energy Mater. 2018, 8, 1-5. [CrossRef]

33. Zhu, D.-J.; Wen, Y.-H.; Xu, Q.; Zhu, Q.-L.; Wu, X.-T. Surface-Amine-Implanting Approach for Catalyst Functionalization: Prominently Enhancing Catalytic Hydrogen Generation from Formic Acid. Eur. J. Inorg. Chem. 2017, 2017, 4808-4813. [CrossRef]

34. Li, Z.; Yang, X.; Tsumori, N.; Liu, Z.; Himeda, Y.; Autrey, T.; Xu, Q. Tandem Nitrogen Functionalization of Porous Carbon: Toward Immobilizing Highly Active Palladium Nanoclusters for Dehydrogenation of Formic Acid. ACS Catal. 2017, 7, 2720-2724. [CrossRef]

35. Mori, K.; Dojo, M.; Yamashita, H. Pd and Pd-Ag nanoparticles within a macroreticular basic resin: An efficient catalyst for hydrogen production from formic acid decomposition. ACS Catal. 2013, 3, 1114-1119. [CrossRef]

36. Martis, M.; Mori, K.; Fujiwara, K.; Ahn, W.S.; Yamashita, H. Amine-functionalized MIL-125 with imbedded palladium nanoparticles as an efficient catalyst for dehydrogenation of formic acid at ambient temperature. J. Phys. Chem.C 2013, 117, 22805-22810. [CrossRef]

37. Mori, K.; Naka, K.; Masuda, S.; Miyawaki, K.; Yamashita, H. Palladium Copper Chromium Ternary Nanoparticles Constructed In situ within a Basic Resin: Enhanced Activity in the Dehydrogenation of Formic Acid. ChemCatChem 2017, 9, 3456-3462. [CrossRef]

38. Navlani-Garcia, M.; Salinas-Torres, D.; Mori, K.; Kuwahara, Y.; Yamashita, H. Enhanced formic acid dehydrogenation by the synergistic alloying effect of PdCo catalysts supported on graphitic carbon nitride. Int. J. Hydrogen Energy 2018. [CrossRef]

39. Navlani-Garcia, M.; Martis, M.; Lozano-Castello, D.; Cazorla-Amoros, D.; Mori, K.; Yamashita, H. Investigation of $\mathrm{Pd}$ nanoparticles supported on zeolites for hydrogen production from formic acid dehydrogenation. Catal. Sci. Technol. 2015, 5, 364-371. [CrossRef]

40. Navlani-Garcia, M.; Mori, K.; Wen, M.; Kuwahara, Y.; Yamshita, H. Size Effect of Carbon-Supported Pd Nanoparticles in the Hydrogen Production from Formic Acid. Bull. Chem. Soc. Jpn. 2015, 1370, 78-80. [CrossRef]

41. Mori, K.; Tanaka, H.; Dojo, M.; Yoshizawa, K.; Yamashita, H. Synergic Catalysis of PdCu Alloy Nanoparticles within a Macroreticular Basic Resin for Hydrogen Production from Formic Acid. Chem. A Eur. J. 2015, 21, 12085-12092. [CrossRef]

42. Navlani-Garcia, M.; Mori, K.; Nozaki, A.; Kuwahara, Y.; Yamashita, H. Investigation of Size Sensitivity in the Hydrogen Production from Formic Acid over Carbon-Supported Pd Nanoparticles. ChemistrySelect 2016, 1, 1879-1886. [CrossRef] 
43. Navlani-Garcia, M.; Mori, K.; Nozaki, A.; Kuwahara, Y.; Yamashita, H. Screening of Carbon-Supported PdAg Nanoparticles in the Hydrogen Production from Formic Acid. Ind. Eng. Chem. Res. 2016, 55, 7612-7620. [CrossRef]

44. Garcia-Aguilar, J.; Navlani-Garcia, M.; Berenguer-Murcia, A.; Mori, K.; Kuwahara, Y.; Yamashita, H.; Cazorla-Amoros, D. Evolution of the PVP-Pd surface interaction in nanoparticles through the case study of formic acid decomposition. Langmuir 2016, 32, 12110-12118. [CrossRef] [PubMed]

45. Wen, M.; Mori, K.; Kuwahara, Y.; Yamashita, H. Plasmonic Au@Pd nanoparticles supported on a basic metal-organic framework: Synergic boosting of H2production from formic acid. ACS Energy Lett. 2017, 2, 1-7. [CrossRef]

46. Wu, Y.; Wen, M.; Navlani-Garcia, M.; Kuwahara, Y.; Mori, K.; Yamashita, H. Palladium nanoparticles supported on titanium doped graphitic carbon nitride for formic acid dehydrogenation. Chem. Asian J. 2017, 12, 860-867. [CrossRef]

47. Bulushev, D.A.; Jia, L.; Beloshapkin, S.; Ross, J.R.H. Improved hydrogen production from formic acid on a Pd/C catalyst doped by potassium. Chem. Commun. 2012, 48, 4184-4186. [CrossRef]

48. Bulushev, D.A.; Beloshapkin, S.; Plyusnin, P.E.; Shubin, Y.V.; Bukhtiyarov, V.I.; Korenev, S.V.; Ross, J.R.H. Vapour phase formic acid decomposition over $\mathrm{PdAu} / \gamma-\mathrm{Al}_{2} \mathrm{O}_{3}$ catalysts: Effect of composition of metallic particles. J. Catal. 2013, 299, 171-180. [CrossRef]

49. Bulushev, D.A.; Sobolev, V.I.; Pirutko, L.V.; Starostina, A.V.; Asanov, I.P.; Modin, E.; Chuvilin, A.L.; Gupta, N.; Okotrub, A.V.; Bulusheva, L.G. Hydrogen production from formic acid over au catalysts supported on carbon: Comparison with Au catalysts supported on $\mathrm{SiO}_{2}$ and $\mathrm{Al}_{2} \mathrm{O}_{3}$. Catalysts 2019, 9, 376. [CrossRef]

50. Jia, L.; Bulushev, D.A.; Podyacheva, O.Y.; Boronin, A.I.; Kibis, L.S.; Gerasimov, E.Y.; Beloshapkin, S.; Seryak, I.A.; Ismagilov, Z.R.; Ross, J.R.H. Pt nanoclusters stabilized by N-doped carbon nanofibers for hydrogen production from formic acid. J. Catal. 2013, 307, 94-102. [CrossRef]

51. Zacharska, M.; Podyacheva, O.Y.; Kibis, L.S.; Boronin, A.I.; Senkovskiy, B.V.; Gerasimov, E.Y.; Taran, O.P.; Ayusheev, A.B.; Parmon, V.N.; Leahy, J.J.; et al. Ruthenium Clusters on Carbon Nanofibers for Formic Acid Decomposition: Effect of Doping the Support with Nitrogen. ChemCatChem 2015, 7, 2910-2917. [CrossRef]

52. Zacharska, M.; Chuvilin, A.L.; Kriventsov, V.V.; Beloshapkin, S.; Estrada, M.; Simakov, A.; Bulushev, D.A. Support effect for nanosized Au catalysts in hydrogen production from formic acid decomposition. Catal. Sci. Technol. 2016, 6, 6853-6860. [CrossRef]

53. Bulushev, D.A.; Zacharska, M.; Shlyakhova, E.V.; Chuvilin, A.L.; Guo, Y.; Beloshapkin, S.; Okotrub, A.V.; Bulusheva, L.G. Single Isolated Pd2+ Cations Supported on N-Doped Carbon as Active Sites for Hydrogen Production from Formic Acid Decomposition. ACS Catal. 2016, 6, 681-691. [CrossRef]

54. Bulushev, D.A.; Zacharska, M.; Lisitsyn, A.S.; Podyacheva, O.Y.; Hage, F.S.; Ramasse, Q.M.; Bangert, U.; Bulusheva, L.G. Single Atoms of Pt-Group Metals Stabilized by N-Doped Carbon Nanofibers for Efficient Hydrogen Production from Formic Acid. ACS Catal. 2016, 6, 3442-3451. [CrossRef]

55. Zacharska, M.; Bulusheva, L.G.; Lisitsyn, A.S.; Beloshapkin, S.; Guo, Y.; Chuvilin, A.L.; Shlyakhova, E.V.; Podyacheva, O.Y.; Leahy, J.J.; Okotrub, A.V.; et al. Factors Influencing the Performance of Pd/C Catalysts in the Green Production of Hydrogen from Formic Acid. ChemSusChem 2017, 10, 720-730. [CrossRef] [PubMed]

56. Bulushev, D.A.; Zacharska, M.; Beloshapkin, S.; Guo, Y.; Yuranov, I. Catalytic properties of PdZn/ZnO in formic acid decomposition for hydrogen production. Appl. Catal. A Gen. 2018, 561, 96-103. [CrossRef]

57. Podyacheva, O.Y.; Bulushev, D.A.; Suboch, A.N.; Svintsitskiy, D.A.; Lisitsyn, A.S.; Modin, E.; Chuvilin, A.; Gerasimov, E.Y.; Sobolev, V.I.; Parmon, V.N. Highly Stable Single-Atom Catalyst with Ionic Pd Active Sites Supported on N-Doped Carbon Nanotubes for Formic Acid Decomposition. ChemSusChem 2018, 11, 3724-3727. [CrossRef]

58. Navlani-Garcia, M.; Mori, K.; Kuwahara, Y.; Yamashita, H. Recent strategies targeting efficient hydrogen production from chemical hydrogen storage materials over carbon-supported catalysts. NPG Asia Mater. 2018, 10, 277-292. [CrossRef]

59. Navlani-Garcia, M.; Mori, K.; Salinas-Torres, D.; Kuwahara, Y.; Yamashita, H. New Approaches Toward the Hydrogen Production From Formic Acid Dehydrogenation Over Pd-Based Heterogeneous Catalysts. Front. Mater. 2019, 6, 44. [CrossRef]

60. Lee, S.; Cho, J.; Jang, J.H.; Han, J.; Yoon, S.P.; Nam, S.W.; Lim, T.H.; Ham, H.C. Impact of d-Band Occupancy and Lattice Contraction on Selective Hydrogen Production from Formic Acid in the Bimetallic Pd3M ( $\mathrm{M}=$ Early Transition 3d Metals) Catalysts. ACS Catal. 2016, 6, 134-142. [CrossRef] 
61. Choi, B.-S.; Song, J.; Song, M.; Goo, B.S.; Lee, Y.W.; Kim, Y.; Yang, H.; Han, S.W. Core-Shell Engineering of Pd-Ag Bimetallic Catalysts for Efficient Hydrogen Production from Formic Acid Decomposition. ACS Catal. 2019, 9, 819-826. [CrossRef]

62. Bulut, A.; Yurderi, M.; Karatas, Y.; Say, Z.; Kivrak, H.; Kaya, M.; Gulcan, M.; Ozensoy, E.; Zahmakiran, M. MnOx-Promoted PdAg Alloy Nanoparticles for the Additive-Free Dehydrogenation of Formic Acid at Room Temperature. ACS Catal. 2015, 5, 6099-6110. [CrossRef]

63. Ke, F.; Wang, L.; Zhu, J. An efficient room temperature core-shell AgPd@MOF catalyst for hydrogen production from formic acid. Nanoscale 2015, 7, 8321-8325. [CrossRef] [PubMed]

64. Huang, Y.; Xu, J.; Long, T.; Shuai, Q.; Li, Q. Reducing agent-structure-activity relationship of PdAg/C catalysts in formic acid decomposition for hydrogen generation. J. Nanosci. Nanotechnol. 2017, 17, 3798-3802. [CrossRef]

65. Ping, Y.; Yan, J.M.; Wang, Z.L.; Wang, H.L.; Jiang, Q. Ag0.1-Pd0.9/rGO: An efficient catalyst for hydrogen generation from formic acid/sodium formate. J. Mater. Chem. A 2013, 1, 12188-12191. [CrossRef]

66. Hu, C.; Mu, X.; Fan, J.; Ma, H.; Zhao, X.; Chen, G.; Zhou, Z.; Zheng, N. Interfacial effects in PdAg bimetallic nanosheets for selective dehydrogenation of formic acid. ChemNanoMat 2016, 2, 28-32. [CrossRef]

67. Huang, Y.; Xu, J.; Ma, X.; Huang, Y.; Li, Q.; Qiu, H. An effective low Pd-loading catalyst for hydrogen generation from formic acid. Int. J. Hydrogen Energy 2017, 42, 18375-18382. [CrossRef]

68. Jiang, Y.; Fan, X.; Xiao, X.; Qin, T.; Zhang, L.; Jiang, F.; Li, M.; Li, S.; Ge, H.; Chen, L. Novel AgPd hollow spheres anchored on graphene as an efficient catalyst for dehydrogenation of formic acid at room temperature. J. Mater. Chem. A 2015, 4, 657-666. [CrossRef]

69. Nabid, M.R.; Bide, Y.; Etemadi, B. Ag@Pd nanoparticles immobilized on a nitrogen-doped graphene carbon nanotube aerogel as a superb catalyst for the dehydrogenation of formic acid. New J. Chem. 2017, 41, 10773-10779. [CrossRef]

70. Yang, L.; Hua, X.; Su, J.; Luo, W.; Chen, S.; Cheng, G. Highly efficient hydrogen generation from formic acid-sodium formate over monodisperse AgPd nanoparticles at room temperature. Appl. Catal. B Environ. 2015, 168-169, 423-428. [CrossRef]

71. Feng, C.; Wang, Y.; Gao, S.; Shang, N.; Wang, C. Hydrogen generation at ambient conditions: AgPd bimetal supported on metal-organic framework derived porous carbon as an efficient synergistic catalyst. Catal. Commun. 2016, 78, 17-21. [CrossRef]

72. Zhang, Z.; Luo, Y.; Liu, S.; Yao, Q.; Qing, S.; Lu, Z.-H. A PdAg-CeO 2 nanocomposite anchored on mesoporous carbon: A highly efficient catalyst for hydrogen production from formic acid at room temperature. J. Mater. Chem. A 2019, 7, 21438-21446. [CrossRef]

73. Zhang, S.; Metin, O.; Su, D.; Sun, S. Monodisperse AgPd alloy nanoparticles and their superior catalysis for the dehydrogenation of formic acid. Angew. Chem. Int. Ed. 2013, 52, 3681-3684. [CrossRef] [PubMed]

74. Yao, F.; Li, X.; Wan, C.; Xu, L.; An, Y.; Ye, M.; Lei, Z. Highly efficient hydrogen release from formic acid using a graphitic carbon nitride-supported AgPd nanoparticle catalyst. Appl. Surf. Sci. 2017, 426, 605-611. [CrossRef]

75. Singh, A.K.; Jang, S.; Kim, J.Y.; Sharma, S.; Basavaraju, K.C.; Kim, M.-G.; Kim, K.-R.; Lee, J.S.; Lee, H.H.; Kim, D.-P. One-Pot Defunctionalization of Lignin-Derived Compounds by Dual-Functional $\mathrm{Pd}_{50} \mathrm{Ag}_{50} / \mathrm{Fe}_{3} \mathrm{O}_{4} / \mathrm{N}-\mathrm{rGO}$ Catalyst. ACS Catal. 2015, 5, 6964-6972. [CrossRef]

76. Akbayrak, S. Decomposition of formic acid using tungsten(VI) oxide supported AgPd nanoparticles. J. Colloid Interface Sci. 2019, 538, 682-688. [CrossRef] [PubMed]

77. Xu, L.; Jin, B.; Zhang, J.; Cheng, D.-G.; Chen, F.; An, Y.; Cui, P.; Wan, C. Efficient hydrogen generation from formic acid using AgPd nanoparticles immobilized on carbon nitride-functionalized SBA-15. RSC Adv. 2016, 6, 46908-46914. [CrossRef]

78. Wan, C.; Yao, F.; Li, X.; Hu, K.; Ye, M.; Xu, L.; An, Y. Bimetallic AgPd Nanoparticles Immobilized on Amine-Functionalized SBA-15 as Efficient Catalysts for Hydrogen Generation from Formic Acid. ChemistrySelect 2016, 1, 6907-6913. [CrossRef]

79. Zhang, X.; Shang, N.; Shang, H.; Du, T.; Zhou, X.; Feng, C.; Gao, S.; Wang, C.; Wang, Z. Nitrogen-decorated porous carbon supported AgPd nanoparticles for boosting hydrogen generation from formic acid. Energy Technol. 2019, 7, 140-145. [CrossRef]

80. Zhang, X.; Shang, N.; Zhou, X.; Feng, C.; Gao, S.; Wu, Q.; Wang, Z.; Wang, C. AgPd-MnOxsupported on carbon nanospheres: An efficient catalyst for dehydrogenation of formic acid. New J. Chem. 2017, 41, 3443-3449. [CrossRef] 
81. Feng, C.; Gao, S.; Shang, N.; Zhou, X.; Wang, C. Super Nanoteragonal ZrO 2 Embedded in Carbon as Efficient Support of PdAg Nanoparticle for Boosting Hydrogen Generation from Formic Acid. Energy Technol. 2018, 6, 2120-2125. [CrossRef]

82. Deng, Q.-F.; Xin, J.-J.; Ma, S.-K.; Cui, F.-J.; Zhao, Z.-L.; Jia, L.-H. Hydrogen Production from the Decomposition of Formic Acid over Carbon Nitride-Supported AgPd Alloy Nanoparticles. Energy Technol. 2018, 6, 2374-2379. [CrossRef]

83. Dai, H.; Xia, B.; Wen, L.; Du, C.; Su, J.; Luo, W.; Cheng, G. Synergistic catalysis of AgPd@ZIF-8 on dehydrogenation of formic acid. Appl. Catal. B Environ. 2015, 165, 57-62. [CrossRef]

84. Dai, H.; Cao, N.; Yang, L.; Su, J.; Luo, W.; Cheng, G. AgPd nanoparticles supported on MIL-101 as high performance catalysts for catalytic dehydrogenation of formic acid. J. Mater. Chem. A 2014, 2, 11060-11064. [CrossRef]

85. Gao, S.-T.; Liu, W.; Feng, C.; Shang, N.-Z.; Wang, C. A Ag-Pd alloy supported on an amine-functionalized $\mathrm{UiO}-66$ as an efficient synergetic catalyst for the dehydrogenation of formic acid at room temperature. Catal. Sci. Technol. 2016, 6, 869-874. [CrossRef]

86. Feng, C.; Hao, Y.; Zhang, L.; Shang, N.; Gao, S.; Wang, Z.; Wang, C. AgPd nanoparticles supported on zeolitic imidazolate framework derived $\mathrm{N}$-doped porous carbon as an efficient catalyst for formic acid dehydrogenation. RSC Adv. 2015, 5, 39878-39883. [CrossRef]

87. Jiang, K.; Xu, K.; Zou, S.; Cai, W.-B. B-doped pd catalyst: Boosting room-temperature hydrogen production from formic acid-formate solutions. J. Am. Chem. Soc. 2014, 136, 4861-4864. [CrossRef]

88. Navlani-Garcia, M.; Salinas-Torres, D.; Mori, K.; Kuwahara, Y.; Yamashita, H. Tailoring the Size and Shape of Colloidal Noble Metal Nanocrystals as a Valuable Tool in Catalysis. Catal. Surv. Asia 2019, 23, 127-148. [CrossRef]

89. Navlani-Garcia, M.; Salinas-Torres, D.; Mori, K.; Leonard, A.F.; Kuwahara, Y.; Job, N.; Yamashita, H. Insights on palladium decorated nitrogen-doped carbon xerogels for the hydrogen production from formic acid. Catal. Today 2019, 324, 90-96. [CrossRef]

90. Yu, Y.; Wang, X.; Liu, C.; Vladimir, F.; Ge, J.; Xing, W. Surface interaction between Pd and nitrogen derived from hyperbranched polyamide towards highly effective formic acid dehydrogenation. J. Energy Chem. 2020, 40, 212-216. [CrossRef]

91. Sun, J.; Qiu, H.; Cao, W.; Fu, H.; Wan, H.; Xu, Z.; Zheng, S. Ultrafine Pd Particles Embedded in Nitrogen-Enriched Mesoporous Carbon for Efficient $\mathrm{H}_{2}$ Production from Formic Acid Decomposition. ACS Sustain. Chem. Eng. 2019, 7, 1963-1972. [CrossRef]

92. Zhou, X.; Huang, Y.; Xing, W.; Liu, C.; Liao, J.; Lu, T. High-quality hydrogen from the catalyzed decomposition of formic acid by Pd-Au/C and Pd-Ag/C. Chem. Commun. 2008, 3540-3542. [CrossRef]

93. Hattori, M.; Shimamoto, D.; Ago, H.; Tsuji, M. AgPd@Pd/TiO 2 nanocatalyst synthesis by microwave heating in aqueous solution for efficient hydrogen production from formic acid. J. Mater. Chem. A 2015, 3, 10666-10670. [CrossRef]

94. Şener, T.; Demirci, U.B.; Gul, F.; Ata, A. Pd- $\mathrm{MnO}_{2}-\mathrm{Fe} / \mathrm{C}$ as electrocatalyst for the formic acid electrooxidation. Int. J. Hydrogen Energy 2015, 40, 6920-6926. [CrossRef]

95. Liu, H.; Huang, B.; Zhou, J.; Wang, K.; Yu, Y.; Yang, W.; Guo, S. Enhanced electron transfer and light absorption on imino polymer capped PdAg nanowire networks for efficient room-temperature dehydrogenation of formic acid. J. Mater. Chem. A 2018, 6, 1979-1984. [CrossRef]

96. Tsuji, M.; Shimamoto, D.; Uto, K.; Hattori, M.; Ago, H. Enhancement of catalytic activity of AgPd@Pd/TiO 2 nanoparticles under UV and visible photoirradiation. J. Mater. Chem. A 2016, 4, 14649-14656. [CrossRef]

97. Xiao, L.; Jun, Y.-S.; Wu, B.; Liu, D.; Chuong, T.T.; Fan, J.; Stucky, G.D. Carbon nitride supported AgPd alloy nanocatalysts for dehydrogenation of formic acid under visible light. J. Mater. Chem. A 2017, 5, 6382-6387. [CrossRef]

98. Liu, H.; Liu, X.; Yang, W.; Shen, M.; Geng, S.; Yu, C.; Shen, B.; Yu, Y. Photocatalytic dehydrogenation of formic acid promoted by a superior PdAg@g- $\mathrm{C}_{3} \mathrm{~N}_{4}$ Mott-Schottky heterojunction. J. Mater. Chem. A 2019, 7, $2022-2026$. [CrossRef]

99. Shan, N.; Zhou, M.; Hanchett, M.K.; Chen, J.; Liu, B. Practical principles of density functional theory for catalytic reaction simulations on metal surfaces-From theory to applications. Mol. Simul. 2017, 43, 861-885. [CrossRef] 
100. Sameera, W.M.C.; Maseras, F. Transition metal catalysis by density functional theory and density functional theory/molecular mechanics. Wiley Interdiscip. Rev. Comput. Mol. Sci. 2012, 2, 375-385. [CrossRef]

101. Norskov, J.K.; Abild-Pedersen, F.; Studt, F.; Bligaard, T. Density functional theory in surface chemistry and catalysis. Proc. Natl. Acad. Sci. USA 2011, 108, 937-943. [CrossRef]

102. Singh, S.; Li, S.; Carrasquillo-Flores, R.; Alba-Rubio, A.C.; Dumesic, J.A.; Mavrikakis, M. Formic acid decomposition on Au catalysts: DFT, microkinetic modeling, and reaction kinetics experiments. AIChE J. 2014, 60, 1303-1319. [CrossRef]

103. Hu, C.; Ting, S.-W.; Chan, K.-Y.; Huang, W. Reaction pathways derived from DFT for understanding catalytic decomposition of formic acid into hydrogen on noble metals. Int. J. Hydrogen Energy 2012, 37, 15956-15965. [CrossRef]

104. Yoo, J.S.; Abild-Pedersen, F.; Norskov, J.K.; Studt, F. Theoretical analysis of transition-metal catalysts for formic acid decomposition. ACS Catal. 2014, 4, 1226-1233. [CrossRef]

105. Cho, J.; Lee, S.; Han, J.; Yoon, S.P.; Nam, S.W.; Choi, S.H.; Lee, K.-Y.; Ham, H.C. Importance of Ligand Effect in Selective Hydrogen Formation via Formic Acid Decomposition on the Bimetallic Pd/Ag Catalyst from First-Principles. J. Phys. Chem. C 2014, 118, 22553-22560. [CrossRef]

106. Yang, Y.; Xu, H.; Cao, D.; Zeng, X.C.; Cheng, D. Hydrogen Production via Efficient Formic Acid Decomposition: Engineering the Surface Structure of Pd-Based Alloy Catalysts by Design. ACS Catal. 2019, 9, 781-790. [CrossRef]

(C) 2019 by the authors. Licensee MDPI, Basel, Switzerland. This article is an open access article distributed under the terms and conditions of the Creative Commons Attribution (CC BY) license (http://creativecommons.org/licenses/by/4.0/). 